Espacio, Tiempo y Forma, Serie II, Historia Antigua, t. 23, 2010, págs. 177-204

\title{
El sistema familiar romano de época clásica y la condición social de la mujer casada en el contexto del mundo antiguo
}

\author{
The Roman Family System of the Classical Period and the \\ Social Condition of the Married Woman in the Context of the \\ Ancient World
}

\author{
Arcadio del CAstillo*
}

\begin{abstract}
RESUMEN
Este trabajo ha pretendido sobre todo efectuar un análisis comparativo entre el derecho familiar de las antiguas

civilizaciones y el de la romana. Y así hemos llegado a la conclusión de que la clave de los grandes logros romanos en este campo descansa en el hecho de que Roma mantuvo su estructura gentilicia, de forma que todas las relaciones jurídicas de la familia romana se fundamentaron exclusivamente sobre bases de tipo gentilicio. Así, Roma pudo impulsar la institución matrimonial, fundamento del sistema familiar, como uno de los ejemplos más característicos de la autonomía de sus instituciones. Este análisis, por otra parte, nos ha permitido también evidenciar hasta qué punto sus
\end{abstract}

ABSTRACT

This work has sought mainly to make a comparative analysis between the Family Law of the Ancient Civilizations and the Roman one. And the conclusion is that the key of the Roman achievements in this field rests in the fact that Rome maintained its gentilitious structure, so that all the juridical relationships of the Roman family were based exclusively on bases of gentilitious type. In this way, Rome could impel the matrimonial institution, base of the familiar system, like one of the most characteristic examples in the autonomy of its institutions. This analysis, on the other hand, has also allowed to evidence to what extent its contributions ended up benefitting the Roman woman clearly.

* E-mail: arcadio.castillo@ua.es. Dirección postal: Universidad de Alicante, Departamento de Prehistoria, Arqueología, Historia Antigua, Filología Griega y Filología Latina, Campus de San Vicente del Raspeig, Ap. 99, 03080 Alicante. Este trabajo ha podido ser llevado a cabo gracias a la consulta de los fondos del Institute of Classical Studies, el Warburg Institute, la School of Oriental and African Studies y la British Library durante nuestra estancia en Londres en abril de 2009. Por lo demás, su texto fue leído en el Paraninfo de la Universidad de Alicante el 25 de septiembre de 2009 como Lección Inaugural del Curso Académico 2009-2010. Las abreviaturas siguen básicamente las pautas de L'Année Philologique y The Oxford Classical Dictionary. 
aportaciones terminaron por beneficiar claramente a la mujer romana.

PALABRAS CLAVE:

Oriente, Grecia, Roma, Derecho de

Familia, Mujer casada.
KEYWORDS:

Orient, Greece, Rome, Family Law, Married Woman

Al analizar los derechos orientales y hebreo1, observamos que las fuentes jurídicas nos presentan un sistema familiar fundamentado en el patriarcado. $Y$ más en concreto sobre los vínculos de sangre, sobre los cuales se entrelazaban las distintas relaciones.

No parece, sin embargo, que el sistema familiar egipcio antiguo tuviera un carácter decididamente patriarcal; de hecho, algunos historiadores han creído reconocer en el mismo la presencia de ciertos elementos matriarcales, aunque J. Gaudemet $^{2}$ considera que no se puede hablar de matriarcado en el sentido estricto del término. En general, parece poder asegurarse tal vez la existencia de elementos esporádicos de derecho matrilineal, pero lo normal es que se trate de un esquema patrilineal, con algunas excepciones notables.

Por lo que atañe al matrimonio en los derechos orientales, éste tenía un carácter esencialmente poligámico. De manera que, junto a una primera esposa, toleraba la existencia de esposas de menor rango.

Tales principios aparecen recogidos con toda nitidez tanto en el código de Ur-Nammu (c. 2100 a.C.) ${ }^{3}$ o en el de Lipit-Ishtar (c. 1930 a.C.) ${ }^{4}$, como en el código de Hammurabi (c. 1750 a.C.) ${ }^{5}$, en las leyes asirias (c. 1076 a.C.) $)^{6}$ y en las fuentes hebráicas ${ }^{7}$.

\footnotetext{
${ }^{1}$ Cf. en general, por ejemplo, VOLTERRA, E., Diritto romano e diritti orientali (R. Accademia delle Scienze dell'Istituto di Bologna. Classe di Scienze Morali), Bologna, 1937, esp. pp. 95-135 y 222-229; GAUDEMET, J., «La conclusion des fiançailles à Rome à l'époque pré-classique», RIDA, 1, 1948, esp. pp. 87-88; ID., «Originalité et destin du mariage romain», en L'Europe e il diritto romano. Studi in memoria di Paolo Koschaker, II, Milano, 1954, esp. pp. 513 y 517-522; ID., «L'originalité des fiançailles romaines», lura, 6, 1955, esp pp. 58-63; ID., «Le statut de la femme dans l'Empire romain», en Recueils de la Socièté Jean Bodin, XI, Bruxelles, 1959, pp. 191-222; ID., Institutions de l'Antiquité, Paris, 1967, pp. 32-49, 61-62, 70-72, 76-77, 91-95 y 116-122; PIRENNE, J., «Le statut de la femme dans l'ancienne Égypte», en Recueils de la Socièté Jean Bodin, XI, pp. 63-77; ID., "Le statut de la femme dans la civilisation hébraïque», en Recueils de la Socièté Jean Bodin, XI, pp. 107-126; CARDASCIA, G., "Le statut de la femme dans les droits cunéiformes», en Recueils de la Socièté Jean Bodin, XI, pp. 79-94; KLIMA, J., «Le statut de la femme à Ugarit d'après les textes accadiens de Ras-Shamra», en Recueils de la Socièté Jean Bodin, XI, pp. 95-105.

${ }^{2}$ GAUDEMET, J., Institutions..., p. 61 n. 3.

${ }^{3}$ Código de Ur-Nammu, 9 (ROTH, M.T., Law Collections from Mesopotamia and Asia Minor (Writings from the Acient World. Society of Biblical Literature, 6), Atlanta, 1995, p. 18).

${ }^{4}$ Código de Lipit-Ishtar, 24-25, 28 y 30 (ROTH, M.T., Law Collections..., pp. 30-32). 114).

${ }^{5}$ Código de Hammurabi, 137-138, 144-146 y 171 (ROTH, M.T., Law Collections..., pp. 107-109 y

${ }^{6}$ Leyes asirias, A40 (ROTH, M.T., Law Collections..., pp. 167-169).

${ }^{7}$ Gen., IV, 19; XVI, 1-3; XXVI, 34; XXVIII, 9; XXIX, 15-30; XXX, 1-18; Ex., XXI, 10; Deut., XXI, 15; I Samuel, XXV, 42-43; XXVII, 3; II Samuel, XX, 3; I Reyes, XI, 1-3.
} 
Entre los hititas parece que la poligamia afectaba exclusivamente a la familia real, de la que formarían parte la reina, esposa asociada a la vida oficial y a la religiosa, otra esposa de segundo rango, y asimismo un harén. Así lo cree J. Gaudemet ${ }^{8}$, quien considera que dicho sistema podía constituir un derecho propio de la familia real o a lo sumo de los grupos nobiliarios. Pero, tales deducciones pueden ser fruto de la escasez de datos sobre el sistema matrimonial del común de la población.

En cambio, hay que decir que en Egipto podría suponerse la inexistencia de la poligamia, pues, según Heródoto, nunca aparece junto a la esposa legítima ninguna otra de inferior categoría, de manera que la monogamia era la costumbre? Sin embargo, la apreciación de Heródoto no parece ser definitiva, en concreto por lo que se refiere a las clases aristocráticas, e incluso en general podría suceder que la monogamia tal vez no siempre se respetase escrupolosamente. Así podría deducirse del testimonio de Diodoro Sículo, quien, refiriéndose a las costumbres matrimoniales egipcias, indica que la clase sacerdotal únicamente tenía una esposa, pero los demás podían tener tantas como quisieran ${ }^{10}$.

En cualquier caso, en estos derechos, el fundamento del matrimonio era la compraventa de la esposa. La persona que tenía a la mujer bajo su potestad la cedía al esposo mediante un determinado pago, si bien el esposo no adquiría la potestad sobre la mujer.

Este sistema perduró en tales derechos, de forma que cuando, pasado el tiempo, el precio de la esposa se convirtió en un hecho meramente simbólico — sin corresponder al valor real de la mujer- , permaneció, sin embargo, como elemento esencial en la celebración del matrimonio.

Por lo demás, en los derechos orientales, el matrimonio se concretaba mediante la redacción de un documento escrito. Tanto en el código de Ur-Nammu ${ }^{11}$ o en las leyes de Eshnunna (c. 1770 a.C.) ${ }^{12}$, como en el código de Hammurabi ${ }^{13}$ o en las leyes neo-babilónicas (c. 700 a.C. $)^{14}$, lo mismo que en documentos egipcios ${ }^{15}$, en las leyes asirias ${ }^{16}$, en las leyes hititas ${ }^{17}$, e igualmente en las fuen-

${ }^{8}$ GAUDEMET, J., Institutions..., p. 91.

${ }^{9}$ Hdt., II, 92, 1.

10 Diod., I, 80, 3.

${ }^{11}$ Código de Ur-Nammu, 11 (ROTH, M.T., Law Collections..., p. 18).

${ }^{12}$ Leyes de Eshnunna, 27-28 (ROTH, M.T., Law Collections..., p. 63).

${ }^{13}$ Código de Hammurabi, 128 (ROTH, M.T., Law Collections..., p. 105). Contrato de matrimonio, perteneciente al reinado de Samshu-iluna (c. 1749-1712): BARTON, G.A., «Contracts», en HARPER, R.F., Assyrian and Babilonian Literature. Selected Transactions, New York, 1904, p. 269.

${ }^{14}$ Leyes neo-babilónicas, 8 (ROTH, M.T., Law Collections..., p. 146). Contratos de matrimonio, pertenecientes a los reinados de Nabucodonosor II (605-562) y de Nabonido (555-539): BARTON, G.A., «Contracts», pp. 269-270.

15 Doc. 18-19 (REVILLOUT, E. y EISENLOHR, A., Corpus Papyrorum Aegypti, I-3, Paris, 1893, pp. 32-33; cf. GRIFFITH, LL, «The Earliest Egyptian Marriage Contracts», Proceedings of the Society of Biblical Archaeology, 31, 1909, pp. 212-220).

${ }^{16}$ Leyes asirias, A30 y 39 (ROTH, M.T., Law Collections..., pp. 164 y 167).

${ }^{17}$ Leyes hititas, 27-30 y 34 (ROTH, M.T., Law Collections..., pp. 220-221; cf. HOFFNER, H.A., The Laws of the Hittites. A Critical Edition (Documenta et Monumenta Orientis Antiqui. Studies in Near Eastern Archaeology and Civilisation, XXIII), Leiden-New York-Köln, 1997, pp. 36-40 y 42). 
tes hebráicas ${ }^{18}$, o en ciertos papiros arameos del siglo V a.C. procedentes de Elefantina ${ }^{19}$, se denota con claridad que el matrimonio debía de ir acompañado de la redacción de un contrato, en el cual se fijaban los pactos patrimoniales.

Pues bien, la existencia de un contrato, al margen de la interpretación que se quiera dar a las fuentes - para algunos historiadores se trataría tan sólo del acuerdo de esponsales-, representa un concepto antitético con la idea que del matrimonio tenían los romanos, para los cuales la voluntad efectiva y continua de los cónyuges era la base fundamental para crear el vínculo, no sometido a término o condición alguna. Y así lo definen las fuentes jurídicas: el matrimonio era un verdadero y propio consortium omnis uitae. Y, al margen de la voluntad de los contrayentes, ningún otro hecho podía dar lugar al surgimiento del vínculo jurídico conyugal.

En definitiva, en la práctica totalidad de los derechos orientales, el matrimonio era siempre el resultado de un determinado acto inicial, esto es, de la redacción de un documento, y existía con independencia de la voluntad recíproca de los cónyuges. Había también una clarísima diferencia entre el concepto de matrimonio egipcio y el romano. $Y$ tal diferencia se aprecia con toda nitidez cuando los magistrados romanos se encontraban ante la necesidad de aplicar a los egipcios su propio derecho matrimonial, como se desprende de algún documento ${ }^{20}$.

El elemento jurídico de la affectio, en sentido romano, era totalmente desconocido para los orientales. Y, por eso, la ruptura del matrimonio tenía que plasmarse de forma reglamentaria, algo que asimismo se aprecia claramente en el código de Ur-Nammu ${ }^{21}$, en el Compendio sumerio de prescripciones de leyes (c. 1700 a.C. $)^{22}$, en las leyes de Eshnunna ${ }^{23}$, en el código de Hammurabi²4, en las leyes asirias ${ }^{25}$, en las leyes hititas ${ }^{26}$, o en las fuentes hebráicas ${ }^{27}$. Y asimismo te-

18 Tobias, VII, 13-14.

${ }_{19}$ P. Aram., B2.4 y 6; B3.3 y 8; B6.1-4 (PORTEN, B. y TARDENI, A., Textbook of Aramaic Documents from Ancient Egypt, II. Contracts, Hebrew University of Jerusalem, 1989, pp. 26-28, 30-33, 60-63, 78-83 y 132-140; cf. COWLEY, A., Aramaic Papyri of the Fifth Century B.C., Oxford, 1923, 9, 15, 18, 36 y 46, pp. 25-29, 44-50, 54-56, 131-132 y 150-152; KRAELING, E., The Brooklyn Museum Aramaic Papyri. New Documents of the Fifth Century B.C. from the Jewish Colony of Elephantine, New York, 1953, 2, 7 y 14, pp. 140-150, 201-222 y 293-296; BLEIBERG, E., Jewish Life in Ancient Egypt. A Family Archive from the Nile Valley, New York, 2002, pp. 26-27).

${ }^{20}$ Cf. por ejemplo, P. Oxy., II, 265, 266 y 273 (GRENFELL, B.P. y HUNT, A.S., The Oxyrhynchus Papyri, II, London, 1899, pp. 235, 238-243 y 258-259; respectivamente, contrato de matrimonio, contrato de divorcio y contrato de cesión tierras a una hija para un posible matrimonio).

${ }^{21}$ Código de Ur-Nammu, 9-10 (ROTH, M.T., Law Collections..., p. 18).

${ }^{22}$ Compendio sumerio de prescripciones de leyes, IV, 12-14 (ROTH, M.T., Law Collections..., p. 50).

${ }^{23}$ Leyes de Eshnunna, 59 (ROTH, M.T., Law Collections..., p. 68).

${ }^{24}$ Código de Hammurabi, 137-141 (ROTH, M.T., Law Collections..., pp. 107-108).

${ }^{25}$ Leyes asirias, A27 y 37-38 (ROTH, M.T., Law Collections..., pp. 163 y 166-167).

${ }^{26}$ Leyes hititas, 26 y 31-33 (ROTH, M.T., Law Collections..., pp. 220-221; cf. HOFFNER, H.A., The Laws of the Hittites..., pp. 34-35 y 40-42).

${ }^{27}$ Deut., XXIV, 1-4. Cf. Eclesiástico, XXV,26. Asimismo la posibilidad se considera en los contratos matrimoniales de los papiros arameos del siglo $\mathrm{V}$ a.C. procedentes de Elefantina: $P$. Aram., B2.4 y 6; B3.3 y 8; B6.1-4 (PORTEN, B. y TARDENI, A., Textbook of Aramaic Documents..., II, pp. 26-28, 30-33, 60-63, 78-83 y 132-140; cf. COWLEY, A., Aramaic Papyri..., 9, 15, 18, 36 y 46, pp. 25-29, 44-50, 54-56, 131-132 y 150-152; KRAELING, E., The Brooklyn Museum Aramaic Papyri..., 2, 7 y 14, pp. 140-150, 201222 y 293-296; E. BLEIBERG, Jewish Life in Ancient Egypt..., pp. 26-27). 
nemos conocimiento, en concreto, de un contrato neo-babilónico de divorcio, perteneciente al reinado de Nabonido ${ }^{28}$; e igualmente de algunos de ellos en Egipto durante la XXVI dinastía (época saita) ${ }^{29}$.

Las diferencias entre el derecho de los pueblos orientales y el derecho romano afectaban asimismo a otros aspectos del sistema familiar.

Por lo que atañe a la institución de los esponsales, en el derecho romano (en época clásica) constituían una simple promesa, privada de forma específica y con efectos sociales más que jurídicos ${ }^{30}$, razón por la cual en cualquier momento se podían lícitamente romper ${ }^{31}$. Buena prueba de ello es que la legislación de Augusto no equiparaba la relación sexual de la prometida al adulterio, sino al estupro -en igualdad con la relación sexual de cualquier otra ciudadana romana-y, por ello, no conllevaba la acusación iure mariti vel patris, sino la iure extranei ${ }^{32}$.

En cambio, en el derecho oriental los esponsales tenían un carácter distinto. En el código de Ur-Nammu ${ }^{33}$ o en el de Lipit-Ishtar ${ }^{34}$, en las leyes de Eshnunna ${ }^{35}$, en el código de Hammurabi ${ }^{36}$, en las leyes neo-babilónicas ${ }^{37}$, en las leyes asirias ${ }^{38}$, en las leyes hititas ${ }^{39}$, así como en las fuentes hebráicas ${ }^{40}$, esta institución se hallaba en conexión directa con el sistema matrimonial, basado en la compraventa de la mujer, que se reflejaba en un contrato, como ya hemos indicado. En tal contexto los esponsales eran un verdadero contrato preliminar, una especie de matrimonio inicial. De forma que, en general, en el derecho oriental la relación sexual con una mujer que ya estuviera afectada por un contrato nupcial aparece tipificada como un delito de adulterio, penado con la muerte.

${ }^{28}$ BARTON, G.A., «Contracts», pp. 270-271.

${ }^{29}$ Cf. REICH, N.J., «A Demotic Divorce. Papyrus University Museum Jar 2, 800 d, 885 in Philadelphia», Mizraim, 1, 1933, pp. 135-139, esp. p. 136. Igualmente la posibilidad se considera en los contratos matrimoniales, cf. doc. 18-19 (REVILLOUT, E. y EISENLOHR, A., Corpus Papyrorum Aegypti, I-3, pp. 32-33).

${ }^{30}$ Dig., XXIII, 1,1. Bastaba el simple consentimiento para constituir los esponsales, Dig., XXIII, 1, 4 pr. y 7. Y, lo mismo que el matrimonio, se realizaban con el consentimiento de los contrayentes, Dig., XXIII, 11-13.

${ }_{31}$ Dig., XXIII, $1,6$.

32 Dig., XLVIII, 5, 14, 6.

${ }^{33}$ Código de Ur-Nammu, 6, 8 y 15 (ROTH, M.T., Law Collections..., pp. 17-18).

${ }^{34}$ Código de Lipit-Ishtar, 29 y 33 (ROTH, M.T., Law Collections..., pp. 32-33).

${ }^{35}$ Leyes de Eshnunna , 17 y 25-26 (ROTH, M.T., Law Collections..., pp. 61-63).

${ }^{36}$ Código de Hammurabi, 155-156, 159-161 y 166 (ROTH, M.T., Law Collections..., pp. 110-113).

${ }^{37}$ Leyes neo-babilónicas, 9 (ROTH, M.T., Law Collections..., pp. 146-147).

${ }^{38}$ Leyes asirias, A30-31 (ROTH, M.T., Law Collections..., pp. 164-165).

${ }^{39}$ Leyes hititas, 28-30 (ROTH, M.T., Law Collections..., p. 221; cf. HOFFNER, H.A., The Laws of the Hittites..., pp. 37-40).

${ }^{40}$ Gen., XXIV, 15-67; XXIX, 15-21; XXXIV, 6-19; Deut., XX, 7; XXII, 23; Jueces, XIV, 2-8; Oseas, III, 1-3. Contrato de esponsales en papiro arameo del siglo $\mathrm{V}$ a.C. procedente de Elefantina: $P$. Aram., B2.5 (PORTEN, B. y TARDENI, A., Textbook of Aramaic Documents..., II, p. 29; cf. COWLEY, A., Aramaic Papyri..., 48, p. 153). 
Asimismo, en el código de Ur-Nammu ${ }^{41}$ o en el de Lipit-Ishtar ${ }^{42}$, en las leyes de Eshnunna ${ }^{43}$, en el código de Hammurabi4 ${ }^{44}$, en las leyes neo-babilónicas ${ }^{45}$, en las leyes asirias ${ }^{46}$, en las leyes hititas ${ }^{47}$ y en las fuentes hebráicas ${ }^{48}$, se aprecia la existencia de aportaciones económicas, tanto por parte del esposo en beneficio de la mujer o su familia, como por parte del padre de la desposada: precio de la mujer, donación nupcial, precio de virginidad y dote. Y asimismo los documentos egipcios - aunque algo tardíos- contienen menciones a la donación nupcial otorgada por el esposo a la mujer ${ }^{49}$.

Todos estos elementos se intercalan jurídicamente con la existencia del matrimonio, constituyendo pertenencias de la esposa; es más, se establecieron normas que regulaban la restitución de tales aportaciones en caso de la ruptura del vínculo conyugal.

En cambio, un único elemento aparece desde antiguo en las fuentes jurídicas y literarias romanas: la dote. Esto es, la aportación a la familia por parte de la mujer, de su paterfamilias o de otra persona en lugar de ellos, con la idea social de contribuir al sostenimiento del matrimonio. Ahora bien, semejante aportación no era un requisito indispensable para la existencia jurídica del matrimonio. Hasta tal punto fue así que la dote era propiedad del esposo mientras duraba el matrimonio ${ }^{50}$. Y, por ello, no existió al principio ningún tipo de acción dotal para restituir a la mujer su dote, una vez roto el matrimonio; y es sólo en época avanzada cuando quedó reconocido y tutelado el derecho de la esposa a recuperar su dote tras la disolución del matrimonio. Así queda claramente de manifiesto en las Noches Aticas de Aulo Gelio, quien señala que durante casi quinientos años desde la fundación de Roma no existieron ni actiones ni cautiones (ni disposiciones legales ni garantías) en relación con la dote de la mujer tanto en Roma como en el Lacio ${ }^{51}$.

${ }^{41}$ Código de Ur-Nammu, 15 (ROTH, M.T., Law Collections..., p. 18).

${ }^{42}$ Código de Lipit-Ishtar, 21, 24, 29 y 32 (ROTH, M.T., Law Collections..., pp. 30-32).

${ }^{43}$ Leyes de Eshnunna , 17-18 y 25-26 (ROTH, M.T., Law Collections..., pp. 61-63).

${ }^{44}$ Código de Hammurabi, 137-138, 149-150, 159-161, 162-164, 166-167, 171-176 y 183 (ROTH, M.T., Law Collections..., pp. 107, 109, 111-116 y 118).

${ }^{45}$ Leyes neo-babilónicas, 8-13 (ROTH, M.T., Law Collections..., pp. 146-148). En el contrato matrimonial perteneciente al reinado de Nabonido, al que ya hemos hecho referencia, se aprecia la existencia de una dote aportada por el padre de la novia: BARTON, G.A., «Contracts», p. 270. 171).

${ }^{46}$ Leyes asirias, A29-31, 38-39, 43 y 45 (ROTH, M.T., Law Collections..., pp. 163-165, 167 y 169 -

47 Leyes hititas, 27-30 y 34-36 (ROTH, M.T., Law Collections..., pp. 220-222; cf. HOFFNER, H.A., The Laws of the Hittites..., pp. 36-40 y 42-44).

${ }^{48}$ Gen., XXXIV, 12; Ex., XXII, 15-16; I Samuel, XVIII, 25. Asimismo en los contratos matrimoniales de los papiros arameos del siglo V a.C. procedentes de Elefantina: P. Aram., B2.4 y 6; B3.3 y 8; B6.1-4 (PORTEN, B. y TARDENI, A., Textbook of Aramaic Documents..., II, pp. 26-28, 30-33, 60-63, 78-83 y 132-140; cf. COWLEY, A., Aramaic Papyri..., 9, 15, 18, 36 y 46, pp. 25-29, 44-50, 54-56, 131-132 y 150-152; KRAELING, E., The Brooklyn Museum Aramaic Papyri..., 2,7 y 14, pp. 140-150, $201-222$ y 293-296; E. BLEIBERG, Jewish Life in Ancient Egypt..., pp. 26-27).

49 Doc. 18-19 (REVILLOUT, E. y EISENLOHR, A., Corpus Papyrorum Aegypti, I-3, pp. 32-33).

${ }^{50}$ Gayo, Inst., III, 95a; Epit., II, 9, 3; Ulp., Reg., VI, 1-2; Dig., XXIII, 3, 1-3; XXIII, 3, 56, 1 у 75-76.

51 Aul. Gel., NA, IV, 3, 1. 
Hemos de tener en cuenta que la introducción de los arrha sponsalia y de la donatio propter nuptias - que se devolvían en caso de ruptura- tuvo lugar a partir del siglo IV, y por influencia oriental.

En cuanto a la diferencia respecto de la condición social de la mujer casada entre orientales y romanos, hay que decir que:

Frente al derecho romano -en el que la esposa era la compañera del esposo, participando de su dignidad, de su rango, de sus honores y de su fortuna (su posición es para los jurisconsultos romanos el elemento objetivo del matrimonio: el honor matrimonii) - , en los derechos orientales, por el contrario, la mujer era considerada, jurídicamente hablando, un ser inferior al hombre.

En algunos casos su situación, al menos en ciertos aspectos, era equiparable al de una esclava. Y, aunque, por ejemplo en el derecho babilónico la mujer, a diferencia de la romana, no estaba sometida a tutela y podía realizar cualquier tipo de negocios jurídicos, su posición en la familia se hallaba lejos de la romana y no asumía la cualidad de compañera del esposo.

La condición de la mujer en Egipto presenta en principio grandes diferencias, puesto que no sólo podía realizar todo tipo de actos jurídicos, como en Babilonia, sino que desempeñaba un importante papel en la familia durante la época del Imperio Antiguo. Y posteriormente parece que incluso podía convertirse en jefe de familia ${ }^{52}$. Pero, hay que decir que la carencia de fuentes jurídicas es prácticamente total hasta el Imperio Nuevo, lo que pone cualquier apreciación en cuarentena. En cualquier caso, en general se aprecia que el papel social principal de la mujer egipcia era básicamente el de esposa y dueña de la casa.

Si analizamos el sistema de la adopción en los derechos orientales también nos encontramos con una notable disparidad frente al esquema romano.

En los derechos sumerio y babilónico, las diversas instituciones que definen el término que implica la adopción se insertaban dentro de la familia doméstica y, por ello, en los vínculos de sangre. Razones de tipo económico constituyen la base de la adopción en estos derechos. Y en ella —-como se desprende del código de LipitIshtar ${ }^{53}$, de una Tablilla sumeria de ejercicio de leyes (c. 1800 a.C. $)^{54}$ y del Compendio sumerio de prescripciones de leyes ${ }^{55}$, de las leyes de Eshnunna ${ }^{56}$, del código de Hammurabi ${ }^{57}$, así como de las leyes asirias ${ }^{58}$ — el adoptado siempre podía ser reclamado por su propia familia o retornar voluntariamente a la casa paterna, en determinados supuestos, cuando se trataba de salvaguardar el interés patri-

\footnotetext{
${ }^{52}$ Cf. por ejemplo, doc. 3 (REVILLOUT, E. y EISENLOHR, A., Corpus Papyrorum Aegypti, l-1, Paris, 1885, pp. 11-13).

${ }^{53}$ Código de Lipit-Ishtar, 20b-c (ROTH, M.T., Law Collections..., p. 30).

54 Tablilla sumeria de ejercicio de leyes, 4-6 (ROTH, M.T., Law Collections..., p. 44).

${ }_{55}$ Compendio sumerio de prescripciones de leyes, IV, 25-30 (ROTH, M.T., Law Collections..., p. 50).

${ }^{56}$ Leyes de Eshnunna, 32-35 (ROTH, M.T., Law Collections..., p. 64).

57 Código de Hammurabi, 185-193 (ROTH, M.T., Law Collections..., pp. 119-120). Contrato de adopción: BARTON, G.A., «Contracts», pp. 271-272.

58 Leyes asirias, A28 (ROTH, M.T., Law Collections..., p. 163).
} 
monial, que constituía el fundamento de la institución. Algunos contratos neo-babilónicos de adopción, por ejemplo, del reinado de Nabonido, han llegado a nuestros días ${ }^{59}$.

En las fuentes hebráicas, en cambio, no aparece ninguna institución que pueda ser equiparable a la adopción. Pero, la importancia que el derecho hebreo otorga a la institución del levirato - que servía para posibilitar que el hermano del esposo muerto se casase con la viuda y pudiera procurarle un heredero, de forma que el primer hijo de esta nueva unión era considerado como hijo del primer marido ${ }^{60}$ _ justifica la inexistencia de una institución como la adopción, cuya finalidad, procurar un heredero, podía satisfacerse mediante el levirato.

Las leyes hititas tampoco mencionan la adopción. Ello es lógico si tenemos en cuenta que, al igual que los hebreos, los hititas contaban con una forma de levirato, que regulaba el orden de los que debían desposar a la viuda: el hermano del difunto, y en su defecto, el padre o el tío ${ }^{61}$.

Tampoco parece que existiese la adopción en el antiguo derecho egipcio. Así se desprende de un documento de la VI dinastía — la carta de Irti a Seankh-en-Ptah, que muestra la imposibilidad de legitimar a un hijo natural o de hacer partícipe a un extraño en la sucesión paterna en el caso de existir algún heredero legítimo de la familia, que en el caso que nos ocupa resultaba ser un sobrino ${ }^{62}$. Sólo, más tardíamente, durante la XXVI dinastía (época saita), una inscripción de Psamético I (664610) nos descubre la adopción de Nitocris, hija de ese rey (en el año noveno de su reinado), por Amenirdis, hija de su predecesor Taharqa (690-664), para ser su hija mayor, tal como la hija de Taharqa fue dada en adopción a Shepenupet, hermana de éste ${ }^{63}$. De hecho, Shepenupet, una hermana del último rey, Taharqa, era la Esposa del Dios Amón de Tebas, cabeza del colegio sacerdotal tebano, el cual disfrutaba de una poderosa influencia política. La autoridad civil del nomo tebano o incluso de todo el Sur se mantenía, al igual que en los últimos años del dominio etiópico, en manos de Mentuemhat. Pero la autoridad de la Esposa del Dios Amón era superior. She-

59 BARTON, G.A., «Contracts», pp. 272-273.

${ }^{60}$ Gen., XXXVIII, 8; Deut., XXV, 5-10; Rut, IV, 5-14. Ciertamente en un papiro arameo del siglo V a.C. procedente de Elefantina: P. Aram., B3.9 (PORTEN, B. y TARDENI, A., Textbook of Aramaic Documents..., II, pp. 84-85; cf. KRAELING, E., The Brooklyn Museum Aramaic Papyri..., 8, pp. 224-231), aparece un contrato de adopción, del año 416 a.C., pero creemos que se trata de una clara influencia del sistema egipcio, pues el esquema del contrato resulta idéntico, siendo una adopción mediante venta, cf. doc. 8 (REVILLOUT, E. y EISENLOHR, A., Corpus Papyrorum Aegypti, I-2, Paris, 1891, p. 24). En P. Oxy., IX, 1206 (HUNT, A.S., The Oxyrhynchus Papyri, IX, London, 1912, pp. 242-244), aunque en este caso no se trata de un esclavo, también se aprecian las mismas especificaciones. Y, por lo demás, se trata de una ficción jurídica para, en realidad, liberar a un esclavo, pues seguramente el personaje que transfiere al esclavo era su padre, habiéndolo tenido con su propia esclava, cf. KRAELING, E., The Brooklyn Museum Aramaic Papyri..., pp. 224-225.

${ }^{61}$ Leyes hititas, 193 (ROTH, M.T., Law Collections..., p. 236; cf. HOFFNER, H.A., The Laws of the Hittites..., p. 152).

62 GARDINER, A.H. y SETHE, K., Egyptian Letters to the Dead. Mainly from the Old and Middle Kingdoms, London, 1928, pp. 1-3. Cf. PIRENNE, J., Histoire des institutions et du droit privé de l'Ancienne Égypte, III, Bruxelles, 1935, pp. 365-369. p. 74)

${ }^{63}$ Estela de Nitocris, esp. II. 2-7 (CAMINOS, R.A., «The Nitocris Adoption Stela», JEA, 50, 1964, 
penupet tenía con ella, como hija adoptiva y heredera aparente, a su propia sobrina, una hija de Taharqa llamada Amenirdis, la cual ostentaba el título de Adoradora del Dios y había sido puesta allí como directa sucesora en el puesto de la Esposa del Dios Amón por su propio padre Taharqa. De esta forma, Psamético I no pretendía desplazar ni a Shepenupet ni a Amenirdis, sino únicamente incardinar a Nitocris como la siguiente en la línea sucesoria, buscando así debilitar a la autoridad civil de Tebas, lo que le proporcionaría el dominio efectivo del Alto Egipto y en definitiva la unión de los dos reinos ${ }^{64}$. Por lo tanto, semejante adopción -al igual que en el derecho babilónico - tenía un carácter fundamentalmente patrimonial: se trataba de buscar sucesores. Por lo demás, las adoptadas no parecen perder los vínculos que les unían con su familia natural, conservaban su nombre y, al tiempo que mantenían sus derechos a la sucesión paterna, adquirían también los mismos derechos a la sucesión del adoptante. En cualquier caso, parece que la adopción en este período se realizaba mediante una ficción jurídica, bajo la apariencia de una venta del adoptado y sus descendientes al adoptante, como se desprende de un documento de hacia el año 536 a.C. ${ }^{65}$.

Resulta, así, obvia la diferencia que existe con el sistema adoptivo romano, en el que se distinguen dos instituciones: la adoptio y la adrogatio. La adoptio daba lugar al ingreso de un extraño en el grupo político de la familia, de manera que quedaba sometido a la potestad del paterfamilias, convirtiéndose por ello en filiusfamilias de éste ${ }^{66}$. Mediante la adrogatio, un paterfamilias quedaba sometido a la potestad de otro paterfamilias, entrando a formar parte de la nueva familia en calidad de filiusfamilias, y entregando así sus propios filii y su propio patrimonio, de manera que su familia se extinguía ${ }^{67}$. Así pues, inserta en el esquema de la familia gentilicia, la adopción romana nada tenía que ver con la adquisición respectiva de la cualidad de hijo y de padre, basada en la unión de vínculos de sangre.

En Grecia ${ }^{68}$, desde la época homérica, el genos no parece haber jugado un papel fundamental en la organización familiar. Es posible que su importancia se limitase a ciertos grupos aristocráticos, pero, desde luego, carecía de relevancia

${ }^{64}$ CAMINOS, R.A., «The Nitocris Adoption Stela», esp. pp. 78-79 y 97.

65 Doc. 8 (REVILLOUT, E. y EISENLOHR, A., Corpus Papyrorum Aegypti, I-2, p. 24); doc. 42 (MALININE, M. y PIRENNE, J., «Documents juridiques égyptiens (Deuxième série)», Archives d'histoire du droit oriental, 5, 1950-1951, pp. 76-77; también, p. 81). Cf. KOZMAN, F., «Les chrériens d'Égypte ont-ils adopté et suivent-ils jusqu'à nos jours la législation justinienne ou uniquement le code théodosien connu sous le nom de coutumier syro-romain?», en Acta Congressus Iuridici Internationalis VII saeculo a decretalibus Gregorii IX et XIV a codice lustiniano promulgatis. Romae 12-17 novembris 1934, II, Roma, 1935, p. 194.

66 Gayo, Inst., I, 99 y 134; Ulp., Reg., VIII, 3 y 5; Dig., I, 7, 1 y 2 pr.; Aul. Gel., NA, V, 19, 1-3.

${ }^{67}$ Gayo, Inst., I, 99 y 107; Ulp., Reg., VIII, 3 y 8; Dig., I, 7, 1, 2 pr. y 2, 2; Aul. Gel., NA, V, 19, 1-2, 4 y 8.

${ }^{68}$ Cf. en general, por ejemplo, VOLTERRA, E., Diritto romano e diritti orientali, esp. pp. 222-226; WOLFF, H.J., «Marriage Law and Family Organization in Ancient Athens. A Study on the Interrelation of Public and Private Law in the Greek City», Traditio, 2, 1944, pp. 43-95; GAUDEMET, J., «La conclusion des fiançailles à Rome...», esp. pp. 89-93; ID., «Originalité et destin...», esp. pp. 513-514 y 522-525; ID., «L'originalité...», esp pp. 63-66; ID., Institutions..., pp. 143-144 y 203-208; LACEY, W.K., The Family in Classical Greece, London, 1968, passim; MADRZEJEWSKI, J., «La Structure juridique du mariage grec», en Scritti in onore di Orsolina Montevecchi, Bologna, 1981, pp. 231-268; CANTARELLA, E., Pandora's Daughters. The Role and Status of Women in Greek and Roman Antiquity, Baltimore-London, 1987, passim. 
en la organización militar, el derecho civil o la legislación penal arcaica. La ley de Dracón sobre el homicidio lo ignora. De manera que la cohesión del grupo familiar (genos) dejó de ser la base esencial, y se orientó hacia un régimen de familia restringida, que constituyó la célula basica. Esta se creaba mediante el matrimonio, agrupaba a padres e hijos, y a ella se asociaba además a los esclavos. En definitiva, la base esencial del sistema familiar griego era la casa (oikos) o el hogar (hestia).

En cambio, en Roma, como veremos posteriormente, el sistema familiar mantuvo el esquema gentilicio.

Cuando se analiza el derecho helénico se puede observar que su régimen matrimonial tampoco tenía nada que ver con el matrimonio romano. Aunque, el matrimonio era monogámico ${ }^{69}$, igual que en Roma, no se encuentran paralelos con el matrimonio romano, a saber:

a) Ni en la antigua forma de matrimonio, consistente en una aparente compraventa de la mujer, que se contrataba por parte del futuro esposo y el kyrios (padre o pariente más cercano), y sin que fuese necesario el consentimiento de la mujer. El negocio jurídico se realizaba siempre entre el futuro esposo y el kyrios de la mujer, y se plasmaba en la entrega de regalos ${ }^{70}$, los cuales podrían representar una compraventa ficticia. Se ha manifestado, sin embargo, que, tanto en los matrimonios de los poemas homéricos como en todos los demás actos sociales, tenía lugar un intercambio de regalos ${ }^{71}$. Y, por lo demás, se entregaba una dote, siendo restituida a la disolución del matrimonio ${ }^{72}$.

b) Ni mucho menos en el tipo de matrimonio por engyesis, que está contemplado, no sólo en el derecho ático, sino también en la mayoría de las ciudades griegas $^{73}$. En este caso, la conclusión del matrimonio, con la entrega efectiva de la no-

${ }^{69}$ Eur., Andr., 177-180; Hdt., II, 92, 1.

70 Hom., II., XVI, 178 y 190; XXII, 472; Od., II, 52-54 y 205-207; VI, 159; VIII, 318-320; XI, 117 y 281-282; XIII, 378; XV, 18; XVI, 390-392; XIX, 528-529; XXI, 161-162.

${ }^{71}$ Sobre este punto FINLEY, M.I., «Marriage, Sale and Gift in the Homeric World», RIDA, $3^{\mathrm{e}}$ série, 2, 1955, pp. 167-194, ha puesto de manifiesto que, puesto que las sociedades tribales usualmente utilizan términos diferentes para el matrimonio y para la compraventa, habría que precisar que la práctica del intercambio de regalos implica un modelo mejor para entender el matrimonio.

${ }^{72}$ Hom., II., IX, 147-156 y 289-298; Od., II, 132-133; VII, 313-314; XX, 341-344.

${ }^{73}$ Aunque, respecto a Esparta, Plutarco $(L y c ., \mathrm{XV}, 3)$ hace referencia al matrimonio por rapto, lo cierto es que, tanto en Esparta como en otras ciudades, la indudable existencia de la dote (pese a Plut., Mor., 227F=Apophthegmata Laconica, Lyc., 15, que mantiene que Licurgo otorgó una ley por la que las mujeres fueron dadas en matrimonio sin una dote) revela que el matrimonio se resolvía por un compromiso previo entre dos familias. Por lo demás, parece que el matrimonio por engyesis no experimentó modificaciones a principios del período helenístico en la Grecia propiamente dicha, como pone de manifiesto VATIN, C., Recherches sur le mariage et la condition de la femme mariée à l'époque héllenistique (Bibliothèque des écoles françaises d'Athènes et de Rome, 216), Paris, 1970, pp. 148-163, apoyándose en Menandro y en ciertas inscripciones. En el caso concreto de los documentos del Egipto lágida, donde ciertos cambios aparecen connotados, el hecho podría tener una exlicación en la perspectiva del ejemplo de la familia egipcia, aunque en formas que se mantienen en el esquema del derecho griego, como ha apuntado PRÉAUX, C., «Le statut de la femme à l'époque hellénistique, principalement en Égypte», en $R e$ cueils de la Socièté Jean Bodin, XI, p. 153 (cf. VATIN, C., Recherches sur le mariage..., pp. 163-178; MADRZEJEWSKI, J., «La Structure juridique...”, p. 247-258). Tal evolución de la institución matrimonial se 
via, aparecía necesariamente precedido de un acto de esponsales llevado a cabo entre el kyrios y el novio ${ }^{74}$, con la presencia de testigos ${ }^{75}$. En ese mismo proceso normalmente se estipulaba la dote y sus condiciones ${ }^{76}$. Se trataba de una promesa de matrimonio, que implicaba una garantía (mediante contrato) dada por el futuro esposo al kyrios de la mujer de tenerla como esposa legítima ${ }^{77}$ : la mujer pasaba así de la autoridad del kyrios a la del marido. Garantía que es de todo punto contraria a la concepción jurídica del matrimonio romano, basado en la voluntad de unión, un elemento intencional que, por lo demás, no necesitaba un acto para crearlo ni tampoco para cesarlo.

c) $\mathrm{Ni}$ en el denominado matrimonio por epidikasia. Una reivindicación de la mujer a título de esposa, mediante una petición ante los tribunales por parte de un familiar, en la que se solicitaba la aceptación como esposo legítimo de una epikleros (hija transmisora de herencia cuando no existían hijos varones) ${ }^{78}$. Se estableció este procedimiento porque la mujer carecía de la capacidad de disponer de la propiedad, excepto a través de un hijo, de forma que la descendencia masculina era necesaria, y los parientes estaban interesados en el matrimonio de la mujer para que los derechos de la familia no se extinguieran, razón por la que esta modalidad matrimonial quedó regulada en la legislación de Solón ${ }^{79}$.

En Grecia la esencia del matrimonio venía determinada por el elemento material de la convivencia. No era el consenso, sino la cohabitación —que se manifestaba a través de la procreación de los hijos ${ }^{80}$ — lo que constituía el matrimonio ${ }^{81}$, de forma que con ella se iniciaba y se disolvía cuando se interrumpía, bien me-

puede igualmente constatar en otros lugares del Oriente griego (cf. VATIN, C., Recherches sur le mariage..., pp. 178-180). Y todo ello conlleva una natural evolución en todo el espacio helenístico, que terminará por posibilitar un cambio. Es por esta razón por lo que hemos renunciado a tratar esta etapa histórica, igual que nos ha ocurrido en lo referente al matrimonio romano postclásico, en el que también la evolución resulta manifiesta. En ambos casos, la evolución vino a producir una clara distinción.

74 Dem., XXVII, 4-5; XXVIII, 15-16; XXIX, 47; XL, 19 y 26; XLI, 6 y 16; XLIV, 49; XLVI, 18; LVII, 41 y 54; LIX, 92 y 106; Iseo, II, 3-5; III, 4, 24-29, 36, 45 y 70; VI, 14; VIII, 19 y 29; IX, 29; Hiper., Athenog., 16. Cf. Hdt., VI, 130, 2; Plut., Alc., VIII, 3; Pólux, III, 34.

${ }^{75}$ Iseo, III, 25-26; Dem., XXX, 21; XLI, 6; LVII, 41. La ausencia de testigos invalidaba la transacción, cf. Iseo, III, 18-20; Dem., XXX, 26.

${ }^{76}$ Dem., XXVIII, 16; XXX, 18 y 21; XL, 19 y 26; XLI, 3 y 6; XLVI, 18; Iseo, II, 3-5; III, 28; Andoc., IV, 13; Plut., Alc., VIII, 3.

${ }_{77}$ No queremos dejar de constatar que CANTARELLA, E., «La engye prima e dopo la legislazione di Solone nel diritto matrimoniale attico», RIL, 98, 1964, pp. 121-161, ha planteado que tal acto de esponsales era en origen solamente una promesa de matrimonio, la cual fue elevada al rango de condición de legitimidad del matrimonio exclusivamente a partir de la legislación de Solón.

78 Dem., XLIII, 13, 16, 20 y 54-55; XLVI, 18 y 22-23; LVII, 41; Iseo, I, 39; III, 46-50, 64 y 74; VI, 14; X, 4-5; Andoc., I, 117-121; Lisias, XXXII, 4; Arist., Ath. Pol., XLIII, 4. Cf. Hdt., VI, 57, 4; e igualmente el proceso general que se marca en el Código de Gortyna, VII, 15-IX, 1 (WILLETTS, R.F., The Law Code of Gortyn (Kadmos Supplement, I), Berlin, 1967, pp. 45-47).

79 Plut., Sol., XX, 2-3; Diod., XII, 18, 3.

${ }^{80}$ Por ello era costumbre que el esposo, tanto con ocasión de su matrimonio como del nacimiento de descendencia, ofreciese a los miembros de su fratría un sacrificio y un banquete nupcial, cf. Dem., XXXIX, 4 y 22; XL, 28; XLIII, 13; LVII, 54; Iseo, III, 30, 70, 73, 75-76 y 79; VII, 13 y 15; VIII, 18-20; Pólux, VIII, 107 (cf. III, 42).

${ }^{81}$ Dem., XXVII, 45; LIX, 122 (cf. también, XXX, 26, 30 y 33-34); Iseo, II, 7; Pólux, III, 44; Jenofonte, Oec., VII, 10-15 y 18-19. 
diante la expulsión de la esposa ${ }^{82}$ o por el abandono del hogar por parte de la mujer $^{83}$. Cuestión distinta es que fuera usual por parte de la esposa registrar por escrito el divorcio en presencia del arconte ${ }^{84}$, a fin de establecer la obligación del esposo de retornar la dote. También era posible la disolución del matrimonio por consentimiento mutuo entre los esposos, cuando la mujer era cedida a otro para contraer nuevas nupcias ${ }^{85}$.

Existían asimismo otros aspectos del sistema familiar que establecían grandes diferencias entre los esquemas griego y romano.

En el derecho de la Grecia clásica, los esponsales eran un acuerdo que precedía al matrimonio. No daban lugar al matrimonio, pero eran obligatorios. Y se realizaban mediante una transacción, conducida en forma legal por el kyrios de la mujer ante testigos. Por lo tanto, no se trataba de un simple contrato de esponsales, sino, de hecho, del primer acto del matrimonio. Así, al igual que en el derecho oriental, aparecían como un contrato preliminar y, por lo tanto, muy diferentes del sentido que los romanos dieron a los esponsales.

En lo referente a la propiedad de la dote durante el matrimonio, en el derecho helénico, desde los primeros tiempos, la propiedad de los bienes dotales correspondía a la esposa, de forma que el esposo sólo tenía derecho al usufructo, por lo que siempre debía de ser restituida cuando se terminaba la relación matrimonial ${ }^{86}$.

En cambio, en Roma la dote pertenecía al esposo, como ya hemos apuntado con anterioridad.

La condición social de la mujer casada era, por lo demás, diferente entre helenos y romanos. La mujer helena, especialmente en Atenas, aunque también en gran parte del mundo griego, si no en su totalidad ${ }^{87}$, vio empeorada su condición social con relación a la época cretense o la micénica. Estaba sometida durante toda su vida a la autoridad del kyrios, el cual administraba sus bienes y defendía sus intereses jurídicamente (no podía concluir actos jurídicos válidos sin la asistencia de su kyrios). Vivía retirada en el gineceo, lugar al que los hombres no tenían acceso. Se mantenía así en reclusión, mientras que en compañía de otras mujeres (de vida más libre) los hombres asistían a las fiestas y a los banquetes. Por lo tanto, aunque ocupaba un lugar importante en la vida familiar, la mujer se hallaba excluída de protagonismo en cuestiones sociales, políticas o económicas.

82 Dem., LIX, 82-84; Iseo, III, 35.

${ }^{83}$ Iseo, III, 8, 35 y 78; Dem., XXX, 8 y 18; Plut., Alc., VIII, 4.

${ }^{84}$ Dem., XXX, 15, 17, 26 y 33; Iseo, III, 78; Andoc., IV, 14; Plut., Alc., VIII, 5-6.

${ }^{85}$ Iseo, II, 7-9; Dem., LVII, 41.

${ }^{86}$ Iseo, II, 3-5 y 9; III, 8; VIII, 8; Dem., XXVII, 4-5, 13-17, 45 y 47; XXX, 8-9, 18-21 y 26; XLI, 5-6; XLV, 28; LIX, 52; Andoc., IV, 13-14; Lisias, XXXII, 6; Hiper., Lycophron, I, 13. Cf. Código de Gortyna, II, 45-48 y III, 17-22 (WILLETTS, R.F., The Law Code of Gortyn, pp. 40-41).

87 Tal situación parece que era algo mejor en las ciudades dorias, y sobre todo en Esparta, como consecuencia de una educación común con los varones (cf. Plut., Lyc., XIV, 2; XV, 1; Mor., 227E=Apophthegmata Laconica, Lyc., 13), aunque la mujer no ocupaba oficialmente ningún lugar en la vida política. 
Realmente, en la sociedad helénica la mujer era percibida como una carga y nunca como una compañera. Justo al contrario que en Roma, civilización en la que la mujer era la compañera del esposo.

El estudio de la adopción en el derecho ático (en el que se regula la misma) ha llevado a varios autores a considerar que tal institución nada tiene que ver con la adopción en el derecho romano, pues en Atenas tenía su razón de ser en motivos de interés diverso: religiosos, políticos y sobre todo patrimoniales ${ }^{88}$. Lo que explica ciertos aspectos originales del derecho ateniense, como la posibilidad de la adopción parcial o la revocación de la adopción ${ }^{89}$ o la existencia de normas que hacían que el adoptado tuviera la facultad o la obligación de desposar a la hija del adoptante ${ }^{90}$.

Así, en el derecho griego, la adopción no tenía como finalidad fundamental, tal como en el derecho romano, la creación de una potestad paternal, que, por otra parte, no existía entre los griegos en el sentido que le daban los romanos. Sino solamente crear entre el adoptante y el adoptado un lazo de parentela que permitiese la transmisión de la propiedad familiar, produciendo sus efectos al margen de la potestad paternal del adoptante sobre el adoptado.

Pues bien, cuando se analiza, por el contrario, el derecho familiar romano ${ }^{91}$ podemos observar un hecho absolutamente distintivo, a saber, que la familia quirita-

${ }^{88}$ Dem., XXXIX, 4; XLI, 3 y 5; XLII, 21; XLIII, 11-13, 37, 77-78 y 81-82; XLIV, 19-26 y 41; Iseo, II, 1116; V, 6; VI, 3 y 5-6; VII, 13-17 y 27-28; IX, 2; X, 4, 9 y 14; XI, 45 y 49; Plut., Them., XXXII, 2; Mor., $843 \mathrm{~A}=$ Vitae decem oratorum, Lyc. Cf. Código de Gortyna, X, 33-XI, 10 (WILLETTS, R.F., The Law Code of Gortyn, pp. 48-49).

${ }^{89}$ Dem., XLI, 5; XLIV, 19-26, 33 y 44; Iseo, VI, 44; IX, 33; X, 11. Cf. Código de Gortyna, XI, 10-17 (WILLETTS, R.F., The Law Code of Gortyn, p. 49).

${ }^{90}$ Dem., XLI, 3; Iseo, III, 69 y 72-73.

91 Cf. en general, por ejemplo, VOLTERRA, E., Diritto romano e diritti orientali, esp. pp. 94-138; ID., La conception du mariage d'après les juristes romains, Padova, 1940, esp. pp. 25-57; GAUDEMET, J., «La conclusion des fiançailles à Rome...», pp. 79-94; ID., "Justum Matrimonium», RIDA, 2, 1949 (Mélanges Fernand de Visscher, I), esp. pp. 309-344; ID., “Originalité et destin...», esp. pp. 513-526; ID., «L'originalité...», pp. 47-77; GARCÍA GARRIDO, M., Ius Vxorium. El régimen patromonial de la mujer casada en el derecho romano, Roma-Madrid, 1958, passim; VILLERS, R., «Le statut de la femme à Rome jusqu'à la fin de la République», en Recueils de la Socièté Jean Bodin, XI, pp. 177-189; BALSDON, J.P.V.D., Roman Women. Their History and Habits, London, 1962, passim; HERRMANN, C., Le rôle judiciaire et politique des femmes sous la République romaine (Coll. Latomus, LXVII), Bruxelles, 1964, passim; ROBLEDA, O., El matrimonio en derecho romano. Esencia, requisitos de validez, efectos, disolubilidad, Roma, 1970, passim; DEL CASTILLO, A., «El papel económico de las mujeres en el Alto Imperio Romano", Revista Internacional de Sociología, 32, 1974, pp. 59-76; ID., La emancipación de la mujer romana en el siglo I d.C., Universidad de Granada, 1976, passim; ID., «The position of women in the Augustan age», LCM, 2, 1977, pp. 167-173; ID., "Apuntes sobre la situación de la mujer en la Roma imperial», Latomus, 38, 1979, pp. 173-187; ID., «La participación femenina en los banquetes y espectáculos romanos como muestra de su actividad social en la obra de Ovidio», AMal, 4, 1981, pp. 401-405; ID., «Ovid on Women Society», Mosaic, 12, 1981, pp. 186-191; ID., «El sistema legislativo como elemento fundamental para el desarrollo femenino en el mundo romano", en La mujer en el mundo antiguo. Actas de las Quintas Jornadas de investigación interdisciplinaria, Universidad Autónoma de Madrid, 1986, pp. 183-193; ID., «La situación de la mujer en la Roma imperial», en ROLDÁN, J.M., BLÁZQUEZ, J.M. y DEL CASTILLO, A., Historia de Roma, II. El Imperio romano, Madrid, 1989, pp. 350358; ID., «Legislación romana y liberación femenina: una relación inconsciente», Lucentum, 7-8, 1988-89, pp. 161-169; GARDNER, J.F., Women in Roman Law and Society, London, 1986, passim; CANTARELLA, E., Pandora's Daughters..., passim; NúÑEZ PAZ, M.I., Consentimiento matrimonial y divorcio en Roma, Universidad de Salamanca, 1988, passim. 
ria se presenta, en su origen, como un verdadero grupo político, creado por razones de orden y defensa. Y esa característica es lo que hace que el sistema familiar romano sea muy distinto de los demás sistemas familiares de la Antigüedad.

En la familia romana todas las relaciones jurídicas se fundamentaban exclusivamente en estructuras gentilicias, de manera que la familia doméstica, basada en los vínculos de sangre, se movía dentro del ámbito jurídico de la familia gentilicia, de ahí que su importancia en el derecho romano fuese menor.

Y, por ello, la patria potestas constituía un aspecto característico de la familia romana. La institución de la patria potestas romana era absolutamente desconocida en el derecho babilónico, en el hitita, en el asirio, en el hebreo o en el egipcio. E igualmente ocurría, de alguna manera, en el mundo helénico. Buena prueba de ello es que Gayo, que debía conocer los derechos helénicos y, en especial, la legislación de Solón, nos presenta esta institución romana como única en el mundo. Y no establece ningún paralelo con poblaciones helénicas, sino sólo con la nación de los gálatas ${ }^{92}$.

Este mismo jurista, en las Instituciones, define la patria potestas como un ius proprium civium Romanorum. Esto no quiere decir que en otras civilizaciones los padres no tuvieran derechos sobre sus hijos, sino que la patria potestas romana era una institución peculiar, con características y efectos distintos. Era una institución del ius civile, mientras que las potestades comunes y naturales, que todo progenitor tiene sobre su descendencia, pertenecían al ius gentium. De hecho, el poder del padre de familia en los otros derechos desaparecía o se atemperaba con la mayoría de edad.

El contenido del derecho de patria potestas era tan fuerte que se suele definir también como el dominio quiritario sobre los hijos. Sus características principales son: se ejercía sobre los liberi (descendientes libres) concebidos como legítimos, esto es, procreados en iustae nuptiae ${ }^{93}$; pero, sólo sobre los descendientes habidos por línea de varón, hijos e hijas habidos de la uxor, nietos y nietas habidos de un hijo, biznietos y biznietas habidos de un nieto, etc., aunque no los habidos de una hija, de una nieta, de una biznieta, etc. ${ }^{94}$; y, aunque se hubieran tenido por línea de varón, no estaban bajo potestad los ya emancipados, pues, pese a ser sanguineos del pater, se hallaban excluidos de la familia de éste ${ }^{95}$; sí estaban, en cambio, bajo potestad los adoptivos ${ }^{96}$. En su ejercicio jurídico la patria potestas era tan estricta como la dominica potestas ${ }^{97}$; más incluso, pues para vender un esclavo bastaba una única mancipatio y por ella el pater perdía la dominica potestas ${ }^{98 ;}$ en

${ }^{92}$ Gayo, Inst., I, 55. Cf. César, BG, VI, 19, 3, que se refiere, sin embargo, a una institución similar de los galos.

\footnotetext{
${ }_{93}$ Gayo, Inst., I, 55-56, 76 y 95; Ulp., Reg., V, 1; Dig., I, 6, 3.

${ }^{94}$ Dig., I, 6, 4; I, 7, 28.

95 Gayo, Inst., I, 127-130, 132 y 134; Ulp., Reg., X, 1-5; Dig., I, 6, 11.

${ }^{96}$ Gayo, Inst., I, 97 y 107; Dig., I, 6, 5.

${ }^{97}$ Dig., I, 6, 1, 1.

${ }^{98}$ Gayo, Inst., I, 17. Cf. Ulp., Reg., I, 6.
} 
cambio, el filius vendido dos veces y manumitido otras tantas todavía no escapaba a la patria potestas ${ }^{99}$.

Al analizar las diferencias existentes entre el derecho romano y los derechos de Oriente y Grecia nos hemos referido a distintas instituciones integradas en el derecho familiar de Roma: los esponsales, la dote y la adopción.

Pero, estimamos conveniente dedicar una atención más particularizada, por sus especiales características, a los elementos originales que ofrece el matrimonio en Roma, según la brillante tesis que desarrolló en sus líneas fundamentales el maestro E. Volterra, así como la relación entre matrimonio y conventio in manum, junto con una descripción del conubium y la condición social de la mujer en Roma.

La institución del matrimonio, fundamento del sistema familiar, es uno de los ejemplos más característicos de la autonomía de las instituciones romanas frente a sus equivalentes en otros derechos de la Antigüedad. Era rigurosamente monogámico (ni siquiera se consideró la necesidad del establecimiento del delito de bigamia en el sistema penal).

No existe ninguna constancia de que existiera una compraventa de la mujer. Al respecto, hemos de decir que de ninguna manera se puede considerar como tal la coemptio, la cual era sencillamente una forma de adquisición de la manus. De hecho, la coemptio se podía llevar a cabo con independencia del matrimonio, y así queda de manifiesto en las Instituciones de Gayo ${ }^{100}$. Era una formalidad puramente imaginaria y, por ello, la compraventa era asimismo imaginaria.

En el derecho romano no era necesario ningún escrito para otorgar validez al matrimonio ${ }^{101}$, y así se deduce de las fuentes. Y por la misma razón tampoco para su disolución mediante el divorcio, que por su naturaleza no podía exigir formas, al igual que no las exigía el matrimonio.

Por lo que atañe al divorcio, parece que, desde los mismos orígenes de Roma, fue posible a tenor de lo que mantiene Plutarco, en el sentido de que Rómulo había dado una norma especificando cuándo y por qué un esposo podía repudiar a su mujer, a la que, en cambio, se le prohibía abandonar a su marido bajo ninguna razón ${ }^{102}$. Ahora bien, a pesar de este testimonio, lo cierto es que la práctica del divorcio debió de ser muy rara durante mucho tiempo, hasta el año 231 a.C., fecha en la que Espurio Carvilio Ruga repudió a su esposa, hecho que se registra como el primero ocurrido en Roma ${ }^{103}$. Aunque, en realidad, no fue éste el primer divorcio ${ }^{104} ; \mathrm{y}$, de hecho, habría que suponer que este caso llamó la atención porque era

\footnotetext{
${ }^{99}$ Gayo, Inst., I, 132 y 134; IV, 79; Ulp., Reg., X, 1.

100 Gayo, Inst., I, 114-115.

${ }^{101}$ Dig., XX, 1, 4; XXII, 4, 4; XXXIX, 5, 31 pr. Cf. Quint., Inst., V, 11, 32.

102 Plut., Rom., XXII, 3.

103 Aul. Gel., NA, IV, 3, 1-2; XVII, 21, 44. Cf. Val. Max., II, 1, 4; Dion. Hal., II, 25, 7; Plut., Rom., XXXV (VI), 4; Numa, XXV (III), 13; Mor., 267C y 278E=Qaest. Rom., 14 y 59.

${ }_{104}$ Cf. Val. Max., II, 9, 2 respecto a Lucio Annio, a quien los censores Marco Valerio Máximo y Cayo Junio Bruto Bubulco despojaron de la dignidad de senador por haber repudiado a su esposa con la que se había casado, siendo aún doncella, sin haber pedido su parecer a ninguno de sus amigos. Tal noticia
} 
el primer divorcio propiciado por la esterilidad de la esposa, o tal vez la notoriedad de este divorcio se debió al hecho de que se planteó con motivo del mismo la necesidad de pactar la devolución, en ciertos casos, de la dote, lo que no era costumbre hasta entonces ${ }^{105}$. Realmente, todo indica a que los divorcios eran un fenómeno muy poco frecuente, lo que aparece confirmado en un texto transmitido por Cicerón: Firmiter enim maiores nostri stabilia matrimonia esse voluerunt ${ }^{106}$. En cualquier caso, posteriormente la práctica del divorcio fue intensificándose. E incluso las mujeres sujetas a la manus pudieron divorciarse y obligar al esposo a renunciar a esa potestad mediante el acto de la remancipatio ${ }^{107}$ o de la diffarreatio ${ }^{108}$. Bastaba una simple insinuación, un aviso al cónyuge, el abandono del domicilio conyugal ${ }^{109} \mathrm{o}$, lo que es más llamativo, el establecimiento de una nueva unión matrimonial ${ }^{110}$, para que quedara legalizada la separación de los esposos. Y, si bien es cierto que existían fórmulas corrientemente utilizadas ${ }^{111}$, no eran necesarias en absoluto para que el divorcio tuviera validez. Y, aunque el emperador Augusto (27 a.C.-14) estableció en su reforma matrimonial una formula precisa en lo referente al divorcio - que consistía en la presencia de siete testigos, ciudadanos romanos púberes, junto a un liberto de la parte divorciante, que tenía la misión de transmitir a la parte contraria la decisión de divorciarse ${ }^{112}$, lo cierto es que tal fórmula no parece que fuera necesaria para la verdadera disolución del matrimonio, sino que tenía la finalidad de liberar al esposo de la acusación de lenocinio y de determinar exactamente el momento en el que la acusación de adulterio contra la mujer (reservada durante dos meses al esposo y al padre, y posteriormente a cualquier persona) debía ser efectuada. Naturalmente, para la mentalidad romana, establecer penas contra los cónyuges que optaban por el divorcio era inconcebible; hubiera representado ir contra su libertad. De manera que ciertas penas pecuniarias que se establecieron no castigaban a los cónyuges que se divorciaban ni tampoco estaban destinadas a penar el divorcio en sí mismo, sino que iban dirigidas contra el cónyuge que hubiera dado un motivo justificado para que se divorciasen de él y a favor del cónyuge inocente. Y, en cualquier caso, el matrimonio no podía perdurar después del divorcio, puesto que ello significaba el cese de la affectio maritalis.

ha de situarse en torno al año 306 a.C., que es el momento en el que se connotan ambos censores en Liv., IX, 43, 25.

${ }^{105}$ Aul. Gel., NA, IV, 3, 2.

106 Cic., Rep., VI, 2, 2. Cf. Sen., Ben., III, 16, 2, que además muestra la magnitud del cambio producido; también, Laud. Tur., I, 27 (texto completo en: CIL, VI, 1527, 31670 y 37053=ILS, 8393 y DURRY, M., Éloge funèbre d'une matrone romaine, Paris, 1950, pp. 5-25); Tert., Apol., VI, 6.

107 Gayo, Inst., I, 137 (cf. también, 137a). Cf. Festo, p. 342L, s.v. Remancipatam.

${ }^{108}$ Cf. Festo, p. 65L, s.v. Diffarreatio.

${ }^{109}$ Dig., XXIII, 2, 33; XXIV, 1, 32, 13; XXIV, 1, 57 y 64. Cf. Cic., Top., IV, 19-20; Suet., Calig., XXXVI, 2; Juv., Sat., VI, 85-86. La restitución de la dote por el esposo era la prueba más concluyente, Dig., XXIII, $2,33$.

${ }^{110}$ Dig., XXIII, 2, 33. Cf. Juv., Sat., X, 338-341; Tac., Ann., XI, 27; Suet., Claud., XXIX, 3; Cass. Dio, LX, 31, 3.

111 Dig., XXIV, 2, 2, 1. Cf. Plauto, Amph., 928; Cas., 210-212; Cic., Phil., II, 28, 69; Juv. Sat., VI, 146-148; Marcial, Epigr., X, 41, 2; XI, 104, 1; Sen., Suas., I, 6; Controv., II, 5.9 (cf. también, I, 6, 5); Quint., Decl. min., CCLXII, 6; Apul., Met., V, 26, 6.

${ }_{112}$ Dig., XXIV, 1, 35 y 2, 9; XLVIII, 5, 44. 
El fundamento jurídico del matrimonio romano estaba basado en la affectio maritalis, en el mero consenso efectivo y continuo entre los cónyuges ${ }^{113}$ (además, obviamente, un matrimonio legítimo implicaba la existencia de tres requisitos, a saber, la diversidad de sexo, haber alcanzado la pubertad, y el consentimiento mutuo). Y producía el surgimiento del vínculo, sin necesidad de ninguna otra ceremonia o formalidad. Ello no quiere decir obviamente que no existiesen las celebraciones previas (sponsalia), ciertas exteriorizaciones (festivitas nuptiarum), o la entrega de una dote (dos). Por otra parte, el consentimiento del paterfamilias, cuando algún contrayente no era sui iuris, sólo era necesario que se manifestase en el caso de los hijos, bastando el no disentimiento evidente en el caso de las hijas ${ }^{114}$; e incluso, en época de Augusto, la lex lulia de maritandis ordinibus dispuso que, en caso de negativa injustificada del paterfamilias, el contrayente pudiese recurrir ante el magistrado, como expresa Marciano ${ }^{115}$.

La existencia de la institución del usus, junto con la usurpatio trinoctii en la ley de las XII Tablas, como formas de establecimiento de la conventio in manum, demuestra que también entonces existía el matrimonio por simple consenso. Las fuentes jurídicas romanas son contundentes en negar absolutamente la necesidad de un documento o de cualquier escrito para la validez del matrimonio.

Llegados a este punto cabe preguntarse lo siguiente: si únicamente la voluntad de los contrayentes (affectio) daba lugar y sostenía al matrimonio romano ¿cómo se insertaban tales esquemas matrimoniales en el sistema gentilicio romano? Pues, a través de otras instituciones, a saber, la conventio in manum y el conubium, que regulaban la entrada de la esposa y de la descendencia dentro de la familia.

E. Volterra ${ }^{116}$ desarrolló una teoría, con la que estamos completamente de acuerdo, que le permitió demostrar la inexistencia de dos tipos diferentes de matrimonio entre los romanos, a saber, cum manu y sine manu. Ello ha venido a poner de manifiesto cómo para la mentalidad romana el matrimonio y la conventio in manum eran cosas muy diferentes. Mediante el matrimonio se creaba una unión

${ }^{113}$ Dig., XXIV, 1, 32, 13; XXXV, 1, 15; XXXIX, 5, 31 pr.; L, 17, 30. Cf. Quint., Inst., V, 11, 32.

114 Dig., XXIII, 2, 2.

${ }^{115}$ Dig., XXIII, 2, 19, aunque aceptando los cambios elaborados en el texto por MORIAUD, P., «Du consentement du père de famille au mariage en droit classique», en Mélanges P.F. Girard. Études de droit romain dédiées à Me P.F. Girard Professeur de droit romain à l'Université de Paris à l'occasion du $60^{\circ}$ anniversaire de sa naissance (26 octobre 1912), II, Paris, 1912, pp. 291-308, p. 303.

${ }_{116}$ VOLTERRA, E., Diritto romano e diritti orientali, p. 112 n. 1; ID., La conception du mariage..., esp. pp. 2-25; ID., «Ancora sulla manus e sul matrimonio», en Studi in onore di Siro Solazzi, Napoli, 1948, pp. 675-688; ID., «Nuove osservazioni sulla conventio in manum», en Atti del Congresso Internazionale di diritto romano e storia del diritto (Verona, 1948), III, Milano, 1951, pp. 29-45; ID., «La conception du mariage à Rome», RIDA, $3^{e}$ série, 2, 1955, esp. pp. 365-372; ID., «Nuove ricerche sulla conventio in manum», MAL, serie VIII, 12, 1966, pp. 251-355; ID., «La conventio in manum e il matrimonio romano», RISG, 95, 1968, pp. 205-226; ID., Istituzioni di diritto privato romano, Roma, 1972, pp. 645-647. Cf. ORESTANO, R., «La struttura giuridica del matrimonio romano del diritto classico al diritto giustinianeo», BIDR, 47, 1940, pp. 154-402; 48, 1941, pp. 88-133; 55-56, 1952, pp. 185-395; GAUDEMET, J., «Observations sur la manus», RIDA, $2^{\mathrm{e}}$ série, 2, 1953, pp. 323-353; DEL CASTILLO, A., «Sobre las formas de adquisición de la manus en el matrimonio», Anuario de Estudios Sociales y Jurídicos, 6, 1977, pp. 359-365. 
conyugal en vistas a asegurar la procreación y la educación de los hijos, mientras que la conventio in manum tenía la finalidad de propiciar la entrada de la mujer en un grupo agnaticio, colocándola bajo la autoridad del jefe de dicho grupo.

Bien es cierto que todo parece indicar que probablemente en un comienzo el matrimonio estuviese acompañado, en la mayoría de las ocasiones, de la conventio in manum, habida cuenta de la importancia que mantenía el grupo agnaticio en los primeros siglos de la historia romana, pero ello no justifica, de ninguna manera, la identificación entre ambos. Naturalmente, en el caso de que la mujer optase por no establecer la conventio in manum, simplemente no pasaba a formar parte integrante del grupo agnaticio del esposo, manteniéndose dentro de su familia, con lo que seguía bajo la potestad de su propio paterfamilias.

El origen de la conventio in manum, y todo lo que hace referencia a las formas de adquisición de ésta, se mantienen en la más profunda oscuridad, lo que ha propiciado que las opiniones que, sobre el particular, existen se hayan polarizado hasta el extremo. Y así, mientras que la mayoría de los autores, si bien con matizaciones, consideran que la confarreatio se limitaba exclusivamente a la clase de los patricios, no falta quien sostenga que esta forma no estaba reservada a esa clase.

Acerca de la coemptio algunos autores aseguran que tuvo su origen en la existencia en épocas remotas de una previa compraventa de la esposa mediante una cantidad estipulada que el marido o su familia pagaban escrupulosamente. Un punto de vista que rechazan algunos autores y sobre el que manifiestan sus dudas otros ${ }^{117}$. Y en cuanto a su utilización, frente a quienes consideran que se circunscribió al elemento plebeyo, no faltan quienes sostienen que se extendió tanto a los patricios como a los plebeyos. Parecidas discrepancias observamos al valorar la forma del usus, que para algunos se circunscribía a las mujeres sui iuris, mientras que otros defienden justamente lo contrario. Pero, muy probablemente las posturas más radicalizadas se refieren al orden de aparición de estas tres formas de establecimiento de la manus. Aunque se viene admitiendo la mayor antigüedad de la confarreatio, basándose, por lo general, en Dionisio de Halicarnaso con referencia a la obra legislativa de los tiempos de Rómulo ${ }^{118}$, algún autor estima que ésta fue la última en aparecer. Y, por lo que atañe a las otras dos formas, esto es, coemptio y usus, casi todos los investigadores aceptan la anterioridad del usus, e incluso algunos de ellos van aún más lejos, afirmando que el usus fue la primera forma en aparecer. Aunque existen también defensores de la anterioridad de la coemptio sobre el usus, llegando incluso a sostener que la coemptio fue la forma más antigua de establecimiento de la manus, no solamente anterior al usus sino también a la confarreatio. De cualquier manera, todas las opiniones a las que hemos hecho alusión no pasan de ser especulaciones, pese a que la mayoría de ellas, por diferentes motivos, consigan pasar la frontera de lo posible.

117 Resulta interesante el planteamiento de MAC CORMACK, G., «Coemptio and Marriage by Purchase», BIDR, 81, 1978, pp. 179-199, quien ha propuesto su origen en la existencia, en los inicios de Roma, de un sistema de intercambio de regalos, como el que puso de manifiesto M.I. Finley para la Grecia de los poemas homéricos.

118 Dion. Hal., II, 25, 2-3. 
Ahora bien, no existe duda alguna de que paulatinamente la conventio in manum fue perdiendo gran parte de la importancia que había tenido, y que en la época tardo republicana y muy especialmente durante el período imperial estaba en franco declive; caminaba hacia su total desaparición, ya que había dejado de ser interesante, particularmente para el elemento femenino, dado que la mujer prefería mantenerse bajo la potestas de su propio padre, cuya autoridad se encontraba en esos momentos muy debilitada, antes que pasar a depender de la de su esposo. La primera manifestación de este hecho (declive de la conventio in manum) la constituye la introducción de la usurpatio trinoctii que quedó establecida mediante una disposición de la ley de las XII Tablas, como nos especifica el testimonio del jurisconsulto Gayo: Itaque lege XII tabularum cautum est, ut si qua nollet eo modo in manum mariti convenire, ea quotannis trinoctio abesset atque eo modo <usum> cuiusque anni interrumperet ${ }^{119}$. Y ello se encuentra apoyado también por Aulo Gelio en la forma siguiente: ...non enim posse impleri trinoctium, quod abesse a viro usurpandi causa ex Duodecim Tabulis deberet... ${ }^{120}$. Este procedimiento abrirá paso a la generalización en la sociedad romana de la contratación de matrimonios que no iban acompañados de la conventio in manum, sin que falten autores que abogan por la existencia del denominado por ellos matrimonio sine manu para la clase plebeya en época anterior.

La definitiva desaparición del usus ${ }^{121}$ se producirá algo después, puesto que la última mención segura, dentro de un contexto, procede de Cicerón ${ }^{122}$, siendo que Gayo lo da como definitivamente desaparecido en su época ${ }^{123}$. Partiendo de estos datos se ha apuntado que su desaparición hubo de consumarse completamente entre la época de Cicerón y el momento de la promulgación de la legislación matrimonial del emperador Augusto. Sin embargo, contra esta opinión, algunos autores han mantenido que el usus se encontraba aún en vigor en el año 57, apoyándose para ello en una referencia sobre el matrimonio de la que fue mujer del emperador Nerón (54-68), Poppea Sabina, y su primer esposo el futuro emperador Otón (69), que aparece consignada por el historiador Tácito y que dice lo siguiente: ...si ultra unam alteramque noctem attineretur, nuptam esse se dictitans nec posse matrimonium amittere... ${ }^{124}$. Según este testimonio, Poppea se encontraría casada con Marco Salvio Otón sin haber contratado la conventio in manum y no quería perder las ventajas que le proporcionaría estar bajo la manus de su marido, lo que aún no había conseguido.

La coemptio ${ }^{125}$, aunque aparece citada por Gayo como forma aún en vigor en su tiempo ${ }^{126}$, su uso debía de ser escaso, si tenemos en cuenta que no aparece

\footnotetext{
${ }^{119}$ Gayo, Inst., I, 111.

120 Aul. Gel., NA, III, 2, 13.

121 Sobre el usus, cf. Gayo, Inst., I, 111; Boecio, II in Cic. Top., III, 14 (PL, LXIV, col. 1071B); Aul. Gel., NA, III, 2, 12-13; Macrob., Sat., I, 3, 9; Serv., In Verg. Georg., I, 31.

122 Cic., Flac., XXXIV, 84.

123 Gayo, Inst., I, 111.

124 Tac., Ann., XIII, 46.

125 Sobre la coemptio, cf. Gayo, Inst., I, 113 y 123; Boecio, II in Cic. Top., III, 14 (PL, LXIV, col. 1071B); Serv., In Verg. Georg., I, 3; In Verg. Aen., IV, 103; Isid., Etym., V, 24, 26.

${ }^{126}$ Gayo, Inst., I, 113-114.
} 
ninguna referencia segura de su aplicación con posterioridad a la contenida en la Laudatio Turiae, de los últimos años del siglo I a.C. ${ }^{127}$.

$\mathrm{Y}$, por lo que respecta a la confarreatio ${ }^{128}$, hemos de decir que, aunque existen referencias acerca de la misma en Gayo ${ }^{129}$, Ulpiano ${ }^{130}$ e indirectamente en una inscripción de los tiempos del emperador Cómmodo (180-192), que menciona a un sacerdos confarreationum et diffarreationum ${ }^{131}$, parece necesario concluir que su utilización era sumamente escasa, circunscribiéndose particularmente, según menciona Gayo, a los cargos religiosos más importantes, tales como los sacerdotes superiores (flamines maiores), es decir, los de Júpiter (Diales), los de Marte (Martiales) y los de Quirino (Quirinales), así como el rey de los sacrificios (rex sacrorum), los cuales solamente podían ser designados de entre aquellos que habían nacido de nupcias celebradas con la confarreatio, y ellos mismos no podían ejercer su sacerdocio sin haber cumplido el mismo requisito ${ }^{132}$. La excepcionalidad de la forma explica la existencia de problemas a la hora de buscar personas idóneas para ocupar estos cargos. En este sentido tenemos noticias del caso concreto del flamen Dialis, de cómo en tiempos del emperador Augusto fue necesario un senatus-consultum por el que se permitía una cierta libertad para la flaminica Dialis, a fin de que únicamente estuviese sometida a la manus de su esposo en lo referente a las cosas sagradas, mientras que respecto de las demás cuestiones ella sería tratada jurídicamente como si no hubiese convenido sujetarse a la manus: (Praeterea mulieres quae in manum conveniunt, in patris potestate esse desinunt. Sed confarreatis nuptiis de flaminica Diali senatusconsulto ex relatione) Maximi et Tuberonis cautum est, ut haec quod ad sacra tantum videatur in manu esse, quod vero ad ceteras causas proinde habeatur, atque si in manum non convenisset ${ }^{133}$. Esta medida se vio reforzada, en tiempos del emperador Tiberio, mediante la promulgación de una ley, como se desprende de la opinión manifestada por Tácito: ...lata lex qua flaminica Dialis sacrorum causa in potestate viri, cetera promisco feminarum iure ageret ${ }^{134}$. Ello, por lo demás, demuestra sin lugar a dudas cómo en esta época las mujeres se mostraban decididamente contrarias a aceptar la sumisión a la manus dentro del matrimonio.

Por otra parte, para los romanos el matrimonio se tornaba nulo si no se cumplía la existencia de los tres elementos básicos, concretados en la diversidad de sexo, la pubertad y el consentimiento mutuo. Pero, a estos tres requisitos era necesario unir otro más para que el matrimonio tuviese efectos jurídicos, especialmente en lo que hace referencia a la descendencia, a la que los romanos

127 Laud. Tur., I, 14.

${ }^{128}$ Sobre la confarreatio, cf. Gayo, Inst., I, 112; Ulp., Reg., IX; Boecio, II in Cic. Top., III, 14 (PL, LXIV, col. 1071B); Serv., In Verg. Georg., I, 31; In Verg. Aen., IV, 103, 339 y 374; Plin., NH, XVIII, 3, 10; Dion. Hal., II, 25, 2-3; Festo, p. 3L, s.v. Aqua et igni; p. 79L, s.v. Flammeo.

${ }^{129}$ Gayo, Inst., I, 112.

130 Ulp., Reg., IX.

${ }^{131} \mathrm{CIL}, \mathrm{X}, 6662=I L S, 1455$.

132 Gayo, Inst., I, 112. Cf. Boecio, II in Cic. Top., III, 14 (PL, LXIV, col. 1071B).

${ }^{133}$ Gayo, Inst., I, 136.

134 Tac., Ann., IV, 16. 
otorgaban una importancia trascendental a la hora de realizar el matrimonio. Tal requisito no era otro que el conubium, el cual hacía el matrimonio legítimo, iustae nuptiae. Cuando faltaba este requisito, según ha mantenido $\mathrm{E}$. Nardi ${ }^{135}$, a nuestro juicio muy acertadamente, el matrimonio era contrario a la legalidad, esto es iniustum, ya que el matrimonio no existía desde el punto de vista jurídico. Ahora bien, no por ello se puede hablar de inexistencia de matrimonio o simplemente de nulidad. Bastaba que los contrayentes manifestasen su deseo de permanecer unidos para que existiese el matrimonio.

En definitiva, en el derecho romano clásico existía un matrimonio si se cumplían unos determinados requisitos, y el mantenimiento del vínculo conyugal se fundamentaba exclusivamente en la permanencia de la affectio maritalis o el animus uxoris, de forma que la inexistencia del conubium, un requisito destinado a otorgar al matrimonio efectos jurídicos, no implicaba la nulidad del matrimonio en sí, sino solamente su ilegitimidad a nivel jurídico, lo que lo convertía en iniustum. En tal supuesto los hijos, como ilegítimos (vulgo quaesiti, vulgo concepti, spuri), no se encontraban sujetos a la potestas del paterfamilias, habida cuenta de que, se les consideraba hijos de la madre, pero la ley no les reconocía padre alguno, pues éste era incierto; ahora bien, el matrimonio como tal no era nulo.

Dicho en otros términos, una cosa era la mera unión matrimonial y otra la capacidad jurídica para contraer tal unión y que ésta fuera legal, lo que conllevaba la legitimidad de la descendencia. Todos los textos apuntan a una idea perfectamente clara: el matrimonio, en cuanto ligado de una manera nítida a la affectio maritalis o al animus uxoris, que era lo que lo sostenía y le daba vida de forma constante, y que se manifiestaba ya desde el principio en el consentimiento mutuo a la hora de contraerlo, no podía ser prohibido en ningún caso. Cuando una referencia textual mantiene una prohibición con respecto al matrimonio ello implica únicamente que no se aceptaba como una unión jurídicamente legal. Es decir, no se podía prohibir el matrimonio, pero sí el conubium, y con ello la posibilidad de que los hijos fuesen legítimos.

De forma que, existiendo conubium, la descendencia era legítima ${ }^{136}$, con lo que se imponía el ius civile y los hijos seguían el estatuto jurídico del padre, pasaban a formar parte de la familia paterna, atribuyendo al padre ciudadano romano, si era sui iuris, la patria potestas sobre ellos (conviertiéndose igualmente en sus herederos, sui heredes) o al paterfamilias, en el caso de que el padre fuese filiusfamilias, aunque sin olvidar que a la muerte o extinción jurídica de éste el padre se con-

135 NARDI, E., La reciproca posizione succesoria dei coniugi privi di conubium (R. Università di Roma. Pubblicazioni dell'Istituto di diritto romano, dei diritti dell'Oriente mediterraneo e di storia del diritto, 7), Milano, 1938, pp. 9-10; ID., «Sui divieti matrimoniali delle leggi augustee», SDHI, 7, 1941, p. 116. Cf. DEL CASTILLO, A., «Reflexiones en torno a la concesión del conubium entre libres de nacimiento y libertos», RIDA, $3^{e}$ série, 41, 1994, pp. 192-194 y 202; ID., «Notas sobre los privilegios concedidos a Publio Ebucio y Fecenia Hispala», $A C, 65,1996$, p. 74; ID., «En torno a la problemática sobre la condición jurídica de Cynthia, musa de Propercio», en NIETO IBÁÑEZ, J.M., Estudios sobre la mujer en la cultura griega y latina, Universidad de León, 2005, p. 188.

${ }_{136}$ Gayo, Inst., I, 55-57; Ulp., Reg., V, 1-3 y 8; Dig., I, 5, 19. 
vertía en sui iuris, adquiriendo ipso iure la patria potestas sobre sus hijos; además, los hijos nacidos de un matrimonio con conubium, eran libres de nacimiento y recibían el status civitatis que tenía el padre en el momento de la concepción; y asimismo, les era atribuido el patronímico, indicado con el praenomen del padre, en genitivo, seguido de filius.

En cambio, si no existía conubium, los hijos eran ilegítimos ${ }^{137}$ y se imponía el ius gentium, según el cual tenían el mismo estatuto jurídico que tuviese la madre en el momento del alumbramiento.

En el derecho romano la mujer casada aparece considerada como la compañera (consors) del esposo ${ }^{138}$, conservando la posición social del marido y participando de su dignidad, de su rango, de sus honores y de su fortuna ${ }^{139}$. Su posición es para los jurisconsultos romanos el elemento objetivo del matrimonio: el honor matrimonii.

De manera que, nada impedía su libre participación en las más diversas actividades, razón por la cual la mujer romana ocupó siempre un lugar importante en la vida social, siendo normalmente admitida en actos sociales, como los banquetes, y ello especialmente durante la época tardo republicana e imperial, cuando las mujeres comían ya recostadas, exactamente igual que los hombres. Asimismo era habitual su presencia en espectáculos, por los que al parecer estaban vivamente interesadas. Es bien conocida la importancia de los ludi en la sociedad romana, y el entusiasmo que despertaban en todas las clases sociales, especialmente el circo, donde mujeres y hombres ocupaban los mismos asientos. Algo que terminó por no ocurrir en los teatros y anfiteatros, debido a la medida de Augusto, que reservó para las féminas las últimas filas al mismo tiempo que retrasaba la hora de su entrada $^{140}$.

Por lo que atañe a cuestiones religiosas, las mujeres mostraron un gran interés por los cultos orientales, que experimentaron un gran desarrollo, y ante los que el estado romano pudo ofrecer una resistencia bastante débil. Ciertamente su influencia se extendió a todas las clases de la sociedad; la libertad que se respiraba en estas religiones debía de ser un estímulo para conseguir nuevos adeptos, especialmente entre las mujeres, que se convertirán en sus más firmes pilares. El hecho de que se viesen tratadas en estos cultos al mismo nivel que los hombres y admitidas en todos los cargos, incluso en los superiores, debía de contribuir no poco al enorme interés del sexo femenino. Las fuentes testimonian asimismo la asiduidad de las mujeres romanas para celebrar el sábado del judaismo. En cuanto al cristianismo, tenemos noticias de numerosas mujeres participando en su culto: entre los primeros mártires su número era notable. Sin embargo, está plenamente constatado que durante los tres primeros siglos del Imperio, el impacto del cristianismo sobre la clase aristocrática fue muy limitado.

${ }^{137}$ Gayo, Inst., I, 64; Ulp., Reg., IV, 2; V, 8-9; Dig., I, 5, 19 y 23-24.

${ }^{138}$ Dig., XXIII, 2, 1.

${ }^{139} \mathrm{Cf}$. por ejemplo, Dig., I, 9, 1, 1; ।, 9, 8.

140 Suet, Aug., XLIV, 2-3. 
En el plano cultural, parece demostrado que las romanas no tenían cerrado el acceso a la cultura; $y$, aunque menospreciadas por algunos escritores, las mujeres cultas parecen abundar, hasta cierto punto. Tenemos constancia incluso de cierto número de mujeres que, así parecen atestiguarlo las fuentes, habría que considerar dedicadas a actividades de tipo intelectual; entre ellas se pueden citar algunas poetisas, biógrafas o incluso mujeres que pudieron brillar en el arte de la oratoria. $Y$, aunque los romanos consideraban los estudios filosóficos fuera del alcance de las mujeres, ciertos escritores las consideraban preparadas para el estudio de esta disciplina.

La mujer romana mantuvo una situación que se puede catalogar de envidiable. Y, sobre todo, desde la Baja República fue adquiriendo una considerable independencia, como consecuencia del progresivo debilitamiento de los vínculos potestativos que anteriormente habían limitado sus posibilidades de acción. Paralelamente su educación fue haciéndose más amplia y profunda, y su participación en la sociedad en que vivía adquirió, poco a poco, más importantes perspectivas de desarrollo.

Aunque, desde luego, las mujeres no podían ejercer ciertas profesiones, de forma que se hallaban legalmente incapacitadas para actuar como banqueros ${ }^{141}$, jueces, abogados o procuradores ${ }^{142}$. Estas prohibiciones se basaban en que los romanos consideraban que ciertas ocupaciones tenían que ser desempeñadas exclusivamente por varones; en razón de tales criterios se impedía también a las mujeres la posibilidad de intercedere pro aliis, establecida hacia mediados del siglo I por el senatus-consultum Velleianum. La disposición prohibía a las mujeres que tomasen dinero a préstamo para otra persona o llevar a efecto una fideiussio ${ }^{143}$. Pero, tales limitaciones no impidieron la participación femenina en todas las demás actividades.

La mujer romana, dueña de sus propios asuntos, aparecía desempeñando igualmente actividades como propietaria, comerciante, industrial, o simplemente como trabajadora libre ganando su propio sustento.

Y, por otra parte, a pesar de ser reconocida como ciudadana, carecía de derechos políticos (hecho usual en todo el contexto del mundo antiguo). No tenía acceso a las magistraturas ni al Senado ni podía votar en los comicios ${ }^{144}$. Ahora bien, ello no le impedía participar en la vida política a través del propio esposo, pues podía intervenir en cualquier aspecto en que su cónyuge estuviera involucrado. Y su influencia en todos los terrenos se incrementó notablemente desde la época tardo republicana, no decayendo durante el Imperio. Desde luego, hay que tener en

${ }^{141}$ Dig., II, 13, 12.

142 Dig., L, 17, 2. Aunque podían ser testigos en un juicio (Dig., XXVIII, 1, 20, 6), no podían actuar como abogados. Esta prohibición no existía antes de mediados del siglo I a.C., cuando la actitud de una mujer abogado, llamada Carfania, forzó al pretor urbano a privar a todas las mujeres de la facultad de postulare pro aliis (Dig., III, 1, 1, 5. Cf. Val. Max., VIII, 3, 2, quien la denomina Caya Afrania).

${ }^{143}$ Paul., Sent., II, 11, 1; Dig., XII, 6, 40 pr.; XVI, 1, 1 pr. y 2, 1; XLVI, 1, 3.

${ }^{144}$ Dig., L, 17, 2. Cf. asimismo, III, 1, 1, 5. 
cuenta que nos referimos concretamente a las mujeres de las clases altas, puesto que el proceso de liberación de las demás fue considerablemente lento con respecto a las anteriores, sin contar, además, la poca documentación que poseemos sobre ellas. Es indudable que la influencia de la mujer en la política se encuentraba en relación directa con el poder que consiguiesen sus maridos o demás parientes varones. En la mayoría de los casos granjearse la amistad de una mujer era el camino más seguro para ganar el favor de un esposo influyente, o promocionarse cerca del emperador; además, el poder de la clientela resultaba extraordinario y las mismas mujeres avalaban y sustentaban el poder de otras. En las provincias, las mujeres de los gobernadores - habida cuenta de que existían muchos casos de mujeres de gobernadores que acompañaban a sus esposos al lugar de su cargo, pues parece que la prohibición de ir con ellos al gobierno provincial debió de quedar derogada después de las guerras civiles - tuvieron tanto poder que podía llegar a compararse con el de sus maridos; salían escoltadas por su guardia personal, acompañaban a sus esposos en las maniobras de las tropas, se solicitaba su mediación ante los mismos a la hora de conseguir beneficios, y participaban activamente en la administración provincial. Las pruebas de la intervención de las mujeres en el gobierno provincial nos las proporcionan: el discurso que Aulo Cecina Severo pronunció ante el Senado, en el año 21, contra las actividades de las mujeres de los gobernadores de las provincias, en el que proponía, además, que se prohibiese a todo magistrado encargado de una provincia hacerse acompañar de su esposa ${ }^{145}$; y la proposición de Marco Valerio Cota Mesalino, en el año 24, para que se estableciese, mediante un senatus-consultum, el que los gobernadores pudiesen ser castigados por las fechorías llevadas a cabo por sus esposas $^{146}$. Sabemos, por otra parte, que, en Pompeya, las mujeres, no pudiendo participar en las elecciones, apoyaban y promocionaban las campañas electorales de sus candidatos predilectos, como se constata en un gran número de inscripciones encontradas $^{147}$.

Desde el siglo II a.C. tuvieron lugar unos cambios que terminaron por resquebrajar el sistema social romano predominante hasta entonces. La subordinación estricta de la esposa al marido, bajo cuya manus se encontraba ${ }^{148}$, había caído en tan franco declive que casi se puede considerar en trance de desaparición. El incremento de la contratación de matrimonios sin establecer la conventio in manum dará lugar a modificaciones en lo que atañe a la capacidad de disposición sobre el patrimonio que pertenecía a la mujer. La permanencia de ésta en su propia familia, sin pasar a la del marido, llevará consigo la necesidad de una separación de los bienes pertenecientes a ambos. Así, la mujer casada mantendrá un patrimonio propio, fuera del alcance del esposo, imposibilitado legalmente para hacer uso de él. En lo referente a su composición, este patrimonio femenino agrupaba lo que los ju-

145 Tac., Ann., III, 33.

146 Tac., Ann., IV, 20.

${ }_{147}$ CIL, IV, 171(=ILS, 6431a), 368, 1168, 3479, 3678(=3294 y ILS, 6414), 3683, 3746, 6610, 7167, 7288, 7291, 7295. 7464, 7469, 7669 y 7749.

148 Gayo, Inst., I, 109-114 y $115 \mathrm{~b}$; II, 159 
ristas conocen con el nombre de res extra dotem, que administraba la misma dueña, directamente o a través de una persona de su confianza que, algunas veces, resultaba ser su propio esposo.

En el año 169 a.C. se aprobó la lex Voconia de mulierum hereditatibus, plebiscito propuesto por el tribuno de la plebe Quinto Voconio Saxa, dirigido contra la creciente independencia de las mujeres y defendido abiertamente por Catón. Prohibía que las mujeres fuesen instituidas herederas por los ciudadanos que, en el último censo, se encontrasen comprendidos en la primera de las clases ${ }^{149}$. Esta medida fue perdiendo poco a poco su significación, especialmente durante el período imperial —ya en tiempos del emperador Calígula (37-41) se puede presumir que había comenzado a dejar de tener aplicación-como consecuencia, por una parte de la caída en desuso de la práctica del censo en este período, y por otra del considerable desarrollo que tomará la costumbre de legar por medio de fideicommissa ${ }^{150}$. Así pues, una mujer tenía todas las facultades para heredar la totalidad de las riquezas pertenecientes a otra persona por muy grandes que éstas fuesen.

$\mathrm{Y}$, junto a la libertad de la mujer para disponer de sus bienes, nos encontramos, desde la época tardo republicana, con otra característica que le permitirá también un más fácil y libre manejo en la administración de los bienes comprendidos en su patrimonio: nos referimos a la progresiva debilitación de la tutela mulieris. En su origen ésta tenía su razón de ser en la idea primitiva del ordenamiento familiar, que tenía como fundamento la autoridad completa del paterfamilias sobre todos los miembros del grupo. De esta manera, la mujer, por encontrarse excluida de la potestas y teniendo su campo de acción limitado al seno de la familia, tenía que estar siempre sometida a la potestas, a la manus o a la tutela del sexo ${ }^{151}$, lo que daba lugar a que fuesen otras personas las que, en definitiva, gestionaban y disponían de sus bienes. De manera que la tutela mulieris resultaba un medio de suplir la potestas del paterfamilias o la manus del marido sobre la mujer mediante los agnados. Pero, la aparición de una nueva forma de tutela, que recibía el nombre de tutela dativa, propició un muy importante cambio en el sistema: en Roma el pretor y la mayoría de los tribunos de la plebe asignaban tutor en virtud de la lex Atilia, y en las provincias tal facultad correspondía al gobernador en virtud de la lex lulia et Titia ${ }^{152}$. Aunque - seguramente

${ }^{149}$ Gayo, Inst., II, 274.
150 Gayo, Inst., II, 286 y $286 a$.
${ }^{151}$ Gayo, Inst., I, 144, 190 y 192-193; Ulp., Reg., XI, 1, 25 y 27. Cf. Cic., Mur., XII, 27; Flac., XXXIV, 84; XXXV, 86; Caecin., XXV, 72-73.

152 Gayo, Inst., I, 185, 195 y 195b-c; Ulp., Reg., XI,18; Dig., XXVI, 5, 1 pr. y 2; XLVI, 6, 7. Datio tutoris ex lege lulia et Titia en: P. Oxy., IV, 702 y FIRA, III, 24 y 25 (GRENFELL, B.P. y HUNT, A.S., The Oxyrhynchus Papyri, IV, London, 1904, pp. 196-197; ARANGIO-RUIZ, V., Fontes luris Romani Antejustiniani, III. Negotia, Firenze, 1943, pp. 66-69). La lex Atilia es atribuida al tribuno de la plebe Lucio Atilio Régulo y, aunque no se conoce la fecha exacta en que se promulgó, parece seguro que no pudo ser posterior al año 186 a.C., cuando Fecenia Hispala, que denunció la conjuración de las Bacanales, declaró haberse hecho nombrar un tutor por medio del pretor y los tribunos (Liv., XXXIX, 9, 7) ni anterior al 367 a.C. en que se creó la pretura. La lex lulia et Titia probablemente sería del año 31 a.C., rogada por el futuro emperador Augusto, en su tercer consulado, y por Marco Ticio, cónsul sufecto de mayo a octubre de ese año. 
con posterioridad a esta última ley, siguiendo el principio que inspiró una disposición legal, en el sentido de que el nombramiento de tutor no era propio del imperium ni de la jurisdicción, sino que solamente competía a aquel al que la ley, el senadoconsulto o el príncipe se lo concedió personalmente ${ }^{153}$ - también les fue otorgado el mismo derecho a todos los magistrados municipales en sus ciudades y territorio de las mismas, e incluso, cuando faltaban los que tenían la atribución de dar tutores, se autorizaba a los decuriones a ejercer esta función, siempre que se decidiese por mayoría ${ }^{154}$. Paralelamente se fue admitiendo en la práctica que el esposo, en su testamento, otorgase a la mujer la facultad de elegir a su tutor. La tutoris optio ofreció la posibilidad de elegir el tutor ${ }^{155}$, lo que permitía a la mujer poder liberarse de la tutela legítima de los agnados, que siempre podía recaer sobre ella. Y la misma jurisprudencia, tomando como modelo la tutela de los patronos sobre sus libertas, propició un recurso para llegar al mismo resultado: la coemptio tutelae evitandae causa. Se trataba de una ficción jurídica, pues consistía en una venta imaginaria o simbólica realizada por la mujer para conseguir liberarse de un tutor molesto. La fórmula nos ha sido transmitida por Gayo, quien manifiesta que la mujer que quería deponer sus tutores y adquirir otro, efectuaba la coemptio con la auctoritas de sus tutores, y luego el comprador (coemptionator) la remancipaba a aquel que ella eligiese, el cual a su vez la manumitía por la vindicta, comenzando entonces a tener por tutor al que la había manumitido, llamado tutor fiduciario: ...si qua velit quos habet tutores deponere et alium nancisci, illis auctoribus coemptionem facit; deinde a coemptionatore remancipata ei cui ipsa velit, et ab eo vindicta manumissa incipit eum habere tutorem, <a> quo manumissa est; qui tutor fiduciarius dicitur... ${ }^{156}$. Ciertamente, el consentimiento del tutor para que la mujer pudiese hacer la coemptio se salvaba, por lo general, mediante un pago. Y quizá se arbitró este sistema porque no parecía lógico que algunas mujeres tuvieran derecho a elegir tutor por vía de su propio esposo, que había sido más condescendiente con ellas, y otras no.

En cualquier caso, desde entonces, la tutela mulieris no será obstáculo alguno para la libre disposición de los bienes por parte de la mujer, puesto que ella podía administrarlos, y la función del tutor consistía simplemente en interponer su auctoritas cuando se consideraba que una transacción podía tener efectos dañinos o adversos para la propiedad de la mujer, quien, por lo demás, en otros aspectos podía incluso forzar al tutor a dar su auctoritas contra su propia voluntad ${ }^{157}$. Las leyes matrimoniales de Augusto liberaron directamente de la

${ }^{153}$ Dig., XXVI, 1, 6, 2.

${ }^{154}$ Dig., XXVI, 5 , 3 y 19. Cf. Lex Ursonensis, 109; Lex Salpensana, 29; Lex Irnitana, 29. La elaboración material de la primera de estas leyes, esto es la de Urso, puede circunscribirse al período que media entre aproximadamente el 20/17 a.C. y el 24 d.C., según ha mentenido en su reciente y excelente contribución CABALLOS RUFINO, A., El nuevo bronce de Osuna y la política colonizadora romana, Universidad de Sevilla, 2006, p. 408. Y naturalmente es de sobra conocido que las otras dos leyes, esto es la de Salpensa y la de Irni, se produjeron en el reinado de Domiciano.

155 Gayo, Inst., I, 150-154. Cf. Liv., XXXIX, 19, 5; Lex Salpensana, 22; Lex Irnitana, 22.

${ }^{156}$ Gayo, Inst., I, 115; cf. asimismo, I, 114, 166, 166a y 195a.

157 Gayo, Inst., I, 190. Aunque siempre excluyendo a los tutores de la denominada tutela legítima, Gayo, Inst., II, 122. 
tutela mulieris, mediante el ius liberorum ${ }^{158}$; y posteriormente el emperador Claudio (41-54) promulgó una disposición que terminaba definitivamente con la tutela legítima de los agnados ${ }^{159}$. Asimismo, las leyes matrimoniales de Augusto propiciaron la liberación de toda mujer que hubiese dado a luz tres hijos, siendo ingenua, de las incapacidades instituidas por la lex Voconia, teniendo en cuenta que tal ley, aunque fraudulentada de múltiples maneras, no había sido de ninguna forma abrogada, como prueba Dion Cassio ${ }^{160}$.

Y, por otra parte, el incremento del número de los divorcios promovió el establecimiento de la obligación de restituir la dote en caso de ruptura del vínculo matrimonial, o incluso por defunción de la esposa. De esta manera, nacerán las cautiones rei uxoriae, consistentes en una previa estipulación a la hora de la constitución de la dote, en la que, entre otras cuestiones, se acordaba la devolución de los bienes dotales por parte del marido ${ }^{161}$. Sin embargo, es necesario precisar que, a pesar de estas novedades claramente favorables a la mujer, durante el período republicano se mantuvo la antigua concepción de la dote como una aportación al marido o a su paterfamilias, sujeta sólo eventualmente a restitución. Un paso adelante llevará a la creación de la actio rei uxoriae, mediante la que la mujer o su paterfamilias, cuando no era sui iuris, podían solicitar la restitución dotal, aunque no se hubiese estipulado previamente ${ }^{162}$.

Asimismo queremos hacer hincapié en un hecho muy llamativo: fue la propia jurisprudencia romana la que propició muchas de las soluciones que favorecían la condición de la mujer romana. Muy probablemente ello fue así porque en Roma eran conscientes de que en muchos extremos del derecho era peor la condición de las mujeres que la de los varones, como indica expresamente Papiniano: In multis iuris nostris articulis deterior est conditio feminarum quam masculorum ${ }^{163}$.

En definitiva, especialmente desde la Baja República las mujeres tomaban parte activa en las más diversas actividades sociales. Como ya hemos indicado, no era extraña su presencia en los banquetes, junto a los varones, en los espectáculos, gritando o apostando como ellos, y en cualquier otro evento. Pero, además, su influencia, si bien en este caso de forma indirecta, era evidente en el terreno político; y desde luego en el terreno económico disfrutaban de libertad de acción en lo concerniente a su patrimonio y a la gestión de sus negocios. La no contratación de

158 Gayo, Inst., I, 145 y 194; III, 44; Ulp., Reg., XXIX, 3. Además, por el mismo principio, las mujeres eran Ilamadas al testamento de los libertos, cf. Ulp., Reg., XXIX, 6-7; Gayo, Inst., III, 46-50. Y, por lo demás, el senatus-consultum Tertullianum, en tiempos del emperador Adriano (117-138), permitió a las madres heredar a sus hijos a título legítimo, aunque exclusivamente en el caso en el que ellos no hubieran otorgado un testamento ni dejaran descendientes, y naturalmente después del padre y de los hermanos consaguíneos, cf. Ulp., Reg., XXVI, 8; Dig., XXXVIII, 17, esp. 2 pr., 1-6 y 15-16.

159 Gayo, Inst., I, 157 y 171; Ulp., Reg., XI, 8.

${ }^{160}$ Cass. Dio, LVI, 10, 2.

${ }^{161}$ Aul. Gel., NA, IV, 3, 2; Ulp., Reg., VI, 5; Dig., esp. XXIII, 3, 21, 23 y 75; XXIII, 4, 1, 1; XXIII, 4, 3, $9,14,17,19,23,26$ pr. y 26, 2; XXIV, 3, 2 pr. y 1; XXIV, 3, 66, 2 y 4.

162 Ulp., Reg., VI, 6; Dig., esp. XXIII, 3, 24, 42, 52 y 73 pr.; XXIII, 5, 18 pr.; XXIV, 3, 2 pr., 1 y 2; XXIV, Max., VIII, 2, 3; Boecio, VI in Cic. Top., XVII, 65 (PL, LXIV, col. 1158B).

${ }_{163}$ Dig., I, 5, 9. 
conventio in manum en el matrimonio -manteniéndose la mujer dentro de su familia sin pasar a la de su esposo, como venía sucediendo, o si era sui iuris únicamente manteniéndose sujeta a las escasas trabas que ahora podía ocasionarle la autoridad de un tutor- proporcionará a la mujer la posibilidad de hallarse en pie de igualdad con el marido, como consecuencia de su independencia económica. Unido a ello, la caída de la tutela mulieris y la escasa eficacia de la lex Voconia por el desuso del censo y las facilidades para eludirla, particularmente mediante los fideicommissa, serán las bases de esta liberación de la mujer. La esposa dotada que dominaba a su marido es un tópico demasiado elocuente en las fuentes. En tales condiciones, no resulta exagerado concluir que, en Roma, la mujer casada pudo gozar de una libertad muy superior a la que tuvieron las mujeres de las demás civilizaciones del mundo antiguo. 